NBER WORKING PAPER SERIES

\title{
ROY MODEL SORTING AND NON-RANDOM SELECTION IN THE VALUATION OF A STATISTICAL LIFE
}

\author{
Thomas DeLeire \\ Christopher Timmins \\ Working Paper 14364 \\ http://www.nber.org/papers/w14364 \\ NATIONAL BUREAU OF ECONOMIC RESEARCH \\ 1050 Massachusetts Avenue \\ Cambridge, MA 02138 \\ September 2008
}

The authors would like to thank Joe Aldy, Matt Kahn, John List, Chris Rohlfs, Laura Taylor, Joe Terza, and all the participants in the Duke Applied Microeconomics Lunch, the Yale and Earth Institute Environmental Economics Seminars, the ASHE biannual meetings, the NBER Summer Institute, and the University of Chicago econometrics workshop for their helpful comments. The views expressed herein are those of the author(s) and do not necessarily reflect the views of the National Bureau of Economic Research.

NBER working papers are circulated for discussion and comment purposes. They have not been peerreviewed or been subject to the review by the NBER Board of Directors that accompanies official NBER publications.

(C) 2008 by Thomas DeLeire and Christopher Timmins. All rights reserved. Short sections of text, not to exceed two paragraphs, may be quoted without explicit permission provided that full credit, including (C) notice, is given to the source. 
Roy Model Sorting and Non-Random Selection in the Valuation of a Statistical Life Thomas DeLeire and Christopher Timmins

NBER Working Paper No. 14364

September 2008

JEL No. J17,J31,Q5,Q51

\section{ABSTRACT}

Wage-hedonics is used to recover the value of a statistical life by exploiting the fact that workers choosing riskier occupations will be compensated with a higher wage. However, Roy (1951) suggests that observed wage distributions will be distorted if individuals select into jobs according to idiosyncratic returns. We illustrate how this type of sorting may bias wage-hedonic VSL estimates and describe two estimators that correct for it. Using data from the CPS, we recover VSL estimates that are three to four times larger than those based on the traditional techniques, statistically significant, and robust to a wide array of specifications.

Thomas DeLeire

La Follette School of Public Affairs

University of Wisconsin - Madison

1225 Observatory Drive

Madison, WI 53706

tdeleire@lafollette.wisc.edu

Christopher Timmins

Department of Economics

Duke University

209 Social Sciences Building

P.O. Box 90097

Durham, NC 27708-0097

and NBER

christopher.timmins@duke.edu 


\section{INTRODUCTION}

Cost-benefit analyses of environmental, workplace, and product safety regulations frequently require estimates of the monetary value of fatality risk reductions. This value typically comes in the form of the value of a statistical life (or, alternatively, the value of a statistical death averted) and is often estimated with wage-hedonic methods. ${ }^{1}$ Workers are compensated for choosing to work in risky jobs. However, workers vary in their idiosyncratic skills and the return to these skills may vary greatly across occupations. In this paper we show that worker sorting based on idiosyncratic returns can bias value of statistical life (VSL) estimates derived with the wage-hedonic technique, and we demonstrate two new empirical strategies to correct for this source of bias. In particular, we employ techniques introduced by Bayer, Khan, and Timmins (2007) to control for polychotomous selection when individuals care about more than just pecuniary returns. These techniques extend the idea originally posited in the Roy model (1951), which explains occupational sorting as a function of only wages. The extension is appropriate for wage-hedonics since, in those models, workers sort across occupations based on nonpecuniary job attributes like fatality risk in addition to their wages. ${ }^{2}$

Correcting for this bias is both empirically important and has significant policy implications. For example, we estimate the VSL for men aged 18-60 to be roughly three

\footnotetext{
${ }^{1}$ The value of a statistical life (VSL) is constructed from individuals' revealed or stated willingness to trade-off other consumption for a marginal reduction in fatality risk (e.g., risk of on-the-job fatality in the context of wage-hedonics). Suppose, for example, that an individual is willing to pay $\$ 40$ for a policy that results in a 1-in-100,000 reduction in the chance of dying. If we were to take 100,000 individuals confronted with this choice, the policy would lead to one fewer death among them. Although none of those individuals know which of them will be saved by the policy, their aggregate willingness to pay is $40 \mathrm{x}$ $\$ 100,000=\$ 4$ million. This number is taken as the VSL. If asked for a willingness to pay to avoid his or her own particular death, any one individual would not be able to give a credible answer to the willingnessto-pay question.

${ }^{2}$ The estimation strategies described below also have applications in other empirical contexts - for example, individuals migrating across cities, where utility is determined by both the wages and local amenities.
} 
to four times larger (and statistically significant) when we correct for "Roy sorting" than the VSL estimated on the same data but with traditional techniques. We find this bias, moreover, in age-specific VSLs that exhibit patterns similar to those found by previous researchers. Our estimates of VSLs for women are reasonable in magnitude and statistically significant, unlike their counterparts based on traditional wage-hedonic techniques. These larger estimates of the VSL (which are also less sensitive to specification) suggest a greater willingness among Americans to pay for reductions in fatality risk through environmental, workplace, and product safety regulations than previously believed.

This paper proceeds as follows. Section 2 describes the Roy model and explains why we should expect sorting based on idiosyncratic returns to yield biased estimates of the VSL calculated with traditional wage-hedonic techniques. Section 3 discusses how our estimators deal with (or fail to address) some other well-known problems with the wage-hedonic approach. Section 4 describes the data we use to implement our estimators, including information about individual workers from the CPS, data describing occupational fatalities from the Bureau of Labor Statistics, and data on other occupational attributes from the Department of Labor's Dictionary of Occupational Titles. Section 5 outlines our first estimation strategy, which semi-parametrically identifies workers' risk preferences in the presence of Roy sorting. Section 6 reports the results of our first estimator alongside results derived from a traditional wage-hedonic procedure, and discusses the results of a number of alternative model specifications. Section 7 describes and implements our second estimation strategy, which makes use of stronger 
independence and distributional assumptions but requires less of the data. Section 8 discusses policy implications and concludes.

\section{ROY SORTING BIAS IN THE WAGE-HEDONIC ESTIMATE OF THE VSL}

Rosen (1986) refers to the theory of equalizing differences as the "fundamental (long-run) market equilibrium construct in labor economics." It explains how the difference in wages between risky and safe jobs is determined - if some jobs are less safe than others, the market equalizing difference (or "compensating differential") is set so that enough workers sort into the risky occupation to clear the market. This was the idea behind Thaler and Rosen's (1975) seminal research on using labor market outcomes to value life - i.e., wage-hedonics.

A second literature in labor economics has examined the implications of idiosyncratic differences in the returns to workers' abilities for their choice of occupation. These implications were first demonstrated by Roy (1951), whose name has since been associated with this class of sorting models. The idea behind the Roy model can be illustrated in a simple example. In an economy with just two occupations, workers who choose occupation \#1 over occupation \#2 receive greater pecuniary returns from this choice than those workers who choose occupation \#2 would have received had they chosen occupation \#1, ceteris paribus. The difference between the wages received by workers in occupation \#1 and occupation \#2 will not, therefore, reflect the difference between the wages that the average worker would have received in each sector. In the simplest possible case, this type of sorting does not create a problem for measuring compensating wage differentials. However, with only minor complications, it can have 
important implications for the ability of wage-hedonics to recover the value of any job attributes (including fatality risk). We demonstrate why with a series of numerical examples. ${ }^{3}$

Suppose that the wage individual $i$ would receive from working in each of two occupations is determined by the following wage equation:

$$
w_{i, j}=\beta R_{j}+\varepsilon_{i, j} \quad j=1,2
$$

where the idiosyncratic component of the wage is drawn from a bivariate normal distribution.

$$
\left(\begin{array}{l}
\varepsilon_{i, 1} \\
\varepsilon_{i, 2}
\end{array}\right) \sim \text { i.i.d. } N\left(\left(\begin{array}{l}
0 \\
0
\end{array}\right),\left(\begin{array}{ll}
1 & 0 \\
0 & 1
\end{array}\right)\right)
$$

Let $R_{j}$ measure the fatality risk in occupation $j$. Occupation \#1 is assumed to be "safe" $\left(R_{1}=0\right)$, whereas occupation \#2 is "risky" $\left(R_{2}=1\right)$. For the sake of simplicity, we set the coefficient on risk in the wage equation $(\beta)$ to be 1 . Figure 1 illustrates the unconditional distribution of wages in each occupation. The compensating wage differential (\$1) is apparent in the difference between the means of these two distributions.

The distributions portrayed in Figure 1 are not, however, the distributions of wages once workers choose their preferred occupation (the conditional wage distribution). Individuals sort across occupations to maximize utility, which is determined in this simple

\footnotetext{
${ }^{3}$ For a formal description of these features of the Roy model, see Heckman and Honore (1990).
} 
example by wages in combination with fatality risk. Individual $i$ receives the following utility from choosing to work in occupation $j$ :

$$
U_{i, j}=w_{i, j}-\beta R_{j}
$$

In the case described in equations (1) and (2), the average wage in occupation \#2 will still be higher than that in occupation \#1 by $\$ 1$ to compensate for its added risk, even after individuals have optimally sorted. Figure 2 demonstrates this result. We construct Figure 2 by simulating a pair of wages for each of one million individuals and assigning that individual to the occupation that gives her the highest utility. We then plot the conditional wage distribution for each occupation (i.e., conditional upon workers having optimally sorted into that sector). Note that, consistent with the predictions of the Roy model, the means of both distributions increase while their variances decrease. Importantly, the difference in the means of the two conditional distributions $(1.57-0.57=$ 1.00) still reflects the true compensating wage differential from which we could derive an unbiased measure of the value of a statistical life. This is because that difference is deducted from utility before Roy sorting occurs and is therefore not distorted by the sorting process.

Now consider a minor modification of the sorting model in equations (1) and (2). In particular, suppose the variance of the unconditional wage distribution in occupation \#1 (i.e., the "safe" occupation) is greater than that in occupation \#2. 


$$
\left(\begin{array}{l}
\varepsilon_{i, 1} \\
\varepsilon_{i, 2}
\end{array}\right) \sim \text { i.i.d. } N\left(\left(\begin{array}{l}
0 \\
0
\end{array}\right),\left(\begin{array}{ll}
2 & 0 \\
0 & 1
\end{array}\right)\right)
$$

Figure 3 shows that the difference in the means of the unconditional wage distributions still reveals the true compensating wage differential. However, when individuals sort, occupation \#1 offers greater opportunities for very high wage draws (large idiosyncratic returns). Optimal sorting yields a bigger upward shift in the mean of the occupation \#1 conditional wage distribution. Comparing the means of the two conditional distributions in Figure 4 reveals a downward bias in the estimate of the compensating differential $(1.46-0.92=0.54)$, implying an understated VSL.

This sorting-induced bias is compounded if individuals' wage draws are positively correlated across occupations. Consider an extreme case:

$$
\left(\begin{array}{l}
\varepsilon_{i, 1} \\
\varepsilon_{i, 2}
\end{array}\right) \sim \text { i.i.d. } N\left(\left(\begin{array}{l}
0 \\
0
\end{array}\right),\left(\begin{array}{cc}
2 & 0.9 \\
0.9 & 1
\end{array}\right)\right)
$$

Now, the individuals receiving the highest draws in occupation \#1 tend to be those individuals who would have received a draw from the upper tail of the occupation \#2 wage distribution. Those left in occupation \#2 tend to be those individuals who receive low draws in both occupations. Figure 5 illustrates that this further compresses the difference in the means of the conditional wage distributions (i.e., down to $1.07-0.80=$ 0.27), making the sorting-induced downward bias in the implied VSL even more severe. The opposite is true if wage draws are negatively correlated across occupations: 


$$
\left(\begin{array}{l}
\varepsilon_{i, 1} \\
\varepsilon_{i, 2}
\end{array}\right) \sim \text { i.i.d. } N\left(\left(\begin{array}{l}
0 \\
0
\end{array}\right),\left(\begin{array}{cc}
2 & -0.9 \\
-0.9 & 1
\end{array}\right)\right)
$$

although in this example, the negative correlation is not strong enough to offset the initial sorting bias. Figure 6 illustrates this case, in which the compensating differential only falls to $1.69-1.06=0.63$.

\subsection{Recovering the VSL in the Presence of Roy Sorting}

In these numerical examples, the direction and size of the bias induced by Roy sorting depends upon the relative sizes of the variances of the unconditional wage distributions in combination with the correlation of individuals' wage draws across occupations. $^{4}$ Heckman and Honoré (1990), however, prove that these unconditional distributions cannot be recovered without first assuming a value for the correlation in individuals' wage draws across occupations (e.g., independence). This leaves the researcher in a difficult position with respect to the bias in the wage-hedonic estimate of the VSL induced by Roy sorting - one needs to first assume a degree of correlation in wage draws in order to recover the unconditional wage distributions, but the degree of correlation itself affects the size of the bias induced by Roy sorting. In Section 5, we demonstrate how one can avoid this problem and correct the sorting bias in the VSL (i) without knowing the unconditional wage distributions and (ii) without assuming anything about the correlation in individuals' wage draws across occupations. This procedure

\footnotetext{
${ }^{4}$ In particular, by making the variance in occupation \#2 larger than that in occupation \#1, we could have made the bias in the VSL go in the opposite direction.
} 
yields an estimate of the VSL that is three times larger than that derived from the traditional wage-hedonic technique.

While straightforward, that estimator does require a lot from the data - in particular, estimates of the minimum order statistics associated with each of a number of conditional wage distributions. While the quality of the wage data we use in our empirical application is quite high, we concede that measurement error and outliers can make it difficult to accurately estimate the minimum order statistic. We subsequently offer a second estimation strategy in section 7 that requires far less of the data. Instead of focusing on the minimum order statistic, it uses information from the entire conditional wage distribution, but requires an assumption of independent wage draws across sectors. That procedure recovers an estimate of the VSL that is more than four times the size of that derived from the comparable wage-hedonic regression. We take the results of these two models as convincing evidence that Roy sorting matters, and leave it to the reader to determine which method is more appropriate for any particular application.

\section{OTHER PROBLEMS WITH THE WAGE-HEDONIC ESTIMATE OF THE VSL}

The wage-hedonic technique has been used extensively (and has been rigorously scrutinized) for decades. We present only a brief overview of the resulting large literature. Viscusi and Aldy (2003) provide a comprehensive discussion of the VSL, paying particular attention to the wage-hedonic technique and the problems that can arise in its implementation. Consider, for example, the role of unobservable individual heterogeneity. One particular form of such heterogeneity is worker productivity. Hwang et al (1992) demonstrate that if workers can be classified as high or low productivity (i.e., 
if there is positive correlation in wage draws across occupations) and if high productivity workers choose to take some of their compensation in the form of lower fatality risk, wages in low-risk occupations will look too high and the estimated fatality risk premium will be too low. This problem has been addressed in earlier work by the use of longitudinal data, identifying individual fixed effects with either (i) workers who switch jobs or (ii) time-varying fatality rates within a job. [See, for example, Brown (1980), Black and Kneisner (2003), and Kniesner et al (2006)] The first estimation approach we describe below will, conveniently, account for this source of bias in that (i) it assumes workers take account of both wages and job attributes (including fatality risk) when choosing an occupation, and (ii) it is robust to any form of correlation in workers' wage draws (i.e., workers can have differing productivities). Like the previous literature, our second estimator requires longitudinal data to address this issue.

A separate problem arises if there is unobservable heterogeneity in individuals' ability to avoid risk. Shogren and Stamland (2002) note that estimates of the VSL will be biased upward if there is heterogeneity in unobservable safety-related skills. The presence of safety-related skills means that not all workers face the same risk on the same job - alternatively, some workers may simply be better at avoiding accidents than others. The compensating differential is determined by the marginal worker, who will have the least amount of safety-related skill among workers in the risky job and thus will face the highest risk. If the average risk faced by workers in the risky job is instead used to calculate the estimate of the VSL, that estimate will be biased upward. Our estimators, in their current form, are unable to allow for idiosyncratic exposure to risk. 
A third problem arises when individuals have heterogeneous preferences for risk. In particular, workers who put less value on safety are more likely to sort into risky jobs, biasing downward wage-hedonic estimates of the compensating risk premium. While panel data and individual fixed effects provide one solution to this sort of preferencebased sorting, researchers have also used information about seatbelt use [Hersch and Viscusi (1990), Hersch and Pickton (1995)] or smoking behavior [Viscusi and Hersch (2001)] to control for risk preferences. While we do not employ data of this sort, our estimation approaches do permit distaste for fatality risk to be controlled for with these sorts of observable characteristics. ${ }^{5}$

There are a number of other problems that may arise when using wage-hedonics to measure the VSL. For example, wage-hedonic techniques often ignore quality of life impacts, as well as the effects of life expectancy. ${ }^{6}$ They usually measure the disutility of facing a particular kind of death that is neither slow nor protracted, and which does not involve a significant latency period. These techniques may not, therefore, be good for valuing avoided deaths from cancer. [Savage (1993), Revesz (1999)] Scotten and Taylor (2007) demonstrate that one should not even treat different sources of on-the-job fatality risk (e.g., accidental, transportation related, and death from violent assault) homogenously in a wage-hedonic equation. Because they focus on labor market outcomes, wagehedonic techniques are not useful for valuing the lives of children and the elderly. For these and other problems, there are a variety of alternative techniques for calculating

\footnotetext{
${ }^{5}$ DeLeire and Levy (2004) provide empirical support for the notion that workers who, based on their observable characteristics such as sex, marital status, and whether they have children, likely have a greater distaste for dangerous work tend to choose safer occupations.

${ }^{6}$ Notable exceptions include Viscusi and Aldy (2006), who find that VSLs follow an inverted-U pattern in age, and Alberini et al (2004), who find lower VSLs for those over the age of 70 using stated preference techniques. Other researchers have also found that the VSL declines at higher ages - see Table 10 in Viscusi and Aldy (2003) for a summary. In contrast, Smith et al (2004) find no evidence of lower VSLs for older individuals.
} 
VSLs including stated preference, human capital approaches, and quantifying the risk tradeoffs agents make in non-labor market settings. ${ }^{7}$ Finally, it is unclear how well actual on-the-job fatality risks proxy for the risks a worker perceives when he decides to accept or reject a wage offer.

Even with all these problems, wage-hedonics remains prevalent in policy making. The EPA has recently reduced the VSL it uses for policy analysis to $\$ 7.22$ million from \$8.04 million. This reduction will have important implications for which policies pass EPA cost-benefit analysis. Both numbers are based on meta-analyses of a variety of VSL studies, many of which used wage-hedonic techniques.

\section{DATA}

We use data from three different sources for both of our estimation strategies.

First, we use data on hourly wage rates and occupations from the Outgoing Rotation Groups of the Current Population Surveys (CPS). Second, we use data on fatal and nonfatal risks associated with each occupation that we construct by merging Bureau of Labor Statistics data on injuries and deaths with CPS data in a procedure described below. Third, we use data on the occupational characteristics (besides injury risks) from the Dictionary of Occupational Titles (DOT).

\footnotetext{
${ }^{7}$ Ashenfelter and Greenstone (2004), for example, use states' decisions to raise speed limits as evidence that the median voter was willing to incur an increased risk of driver death in exchange for lower travel times. Atkinson and Halvorsen (1990), Dreyfus and Viscusi (1995), and Li (2006) look at the willingness of automobile buyers to trade-off risk of death with operating expenditures and purchase price. Blomquist (1979) and Hakes and Viscusi (2007) use drivers' decisions to employ seatbelts in order to recover estimates of the VSL, and Carlin and Sandy (1991) do so with data on individuals' decisions to use child safety seats. Portney (1981) and Gayer, Hamilton, and Viscusi (2000) use tradeoffs between housing expenditures and mortality from air pollution and cancer (caused by proximity to Superfund sites), respectively.
} 
We record wages and occupations from the CPS Outgoing Rotation Groups Surveys from 1983 through 2002. We restrict the data to these years because 1983 and 2002 are the first and last years that the 1980 occupational classification was used in the CPS. In particular, to determine occupation we use responses to the question "What kind of work was ... doing [last week]?" Our sample includes all individuals who were employed during the survey week. This yields data on 3,434,820 workers.

We assign fatal and non-fatal injury risks to each occupation using data from the BLS Survey of Occupational Injuries and Illnesses and the Census of Fatal Occupational Injuries. These data provide counts of injuries and fatalities at the 3-digit occupation level from 1992 to 1999; there is also information on the severity of non-fatal injuries, including the median number of days missed from work per injury within an occupation. ${ }^{8}$ In some cases the data are aggregated across 3-digit occupations; we aggregate all data to correspond to the 2-digit detailed occupation recodes in the CPS. ${ }^{9}$ We use monthly CPS data to calculate hours worked over this period in each category to transform the counts into risks (the number of injuries per 100 full-time workers). ${ }^{10}$ We also calculate "anticipated" days of work lost due to nonfatal injury by multiplying the risk of nonfatal injury by the median days lost per injury within an occupation. We then average over the period 1992-1999 in order to minimize the effects of year-to-year noise (as we demonstrate below, we do not need time variation in fatality risk for identification, even without assuming independence). Average annual risk of death on the job is 0.005 for all

\footnotetext{
${ }^{8}$ Note that simply being able to miss days from work after a non-fatal injury may be a positive amenity associated with many jobs.

${ }^{9}$ The categories do not correspond perfectly to the Census detailed occupation recodes; we collapse codes 40,41 , and 42 into a single category since the fatality data are not available for these categories in a way that can be disaggregated.

${ }^{10}$ A full-time worker is assumed to work 2,000 hours/year, so that the risks we calculate are per 200,000 hours worked.
} 
men (or one for every 25,000 men) and 0.002 for all women (or one for every 50,000 women).

We also use data on other job attributes from the Dictionary of Occupational Titles. The DOT is a reference manual compiled by the U.S. Department of Labor that provides information about occupations. It attempts both to define occupations in a uniform way across industries and to assess the characteristics of occupations. While the occupational characteristics in the DOT were not collected from a nationally representative survey of firms and little detail on sampling or response rates is available, they are the best data available on the characteristics of occupations. The analysis of occupational characteristics was conducted through on-site observation and interviews with employees. The DOT data were constructed by analysts assigning numerical codes to 43 job traits. We create six aggregate variables from the underlying DOT variables to describe occupational characteristics: substantive complexity, motor skills, physical demands, working conditions, creative skills, and interactions with people. A detailed list of the variables used to construct these data is provided in Table 1. Table 2 summarizes the attributes of each occupation. The highest risk occupations (in order) are (1) forestry and fishing, (2) motor vehicle operations, (3) other transportation occupations, (4) farm workers, and (5) construction, freight, labor. All other occupations average fewer than one death per 10,000 workers each year.

The data used to construct hourly wage rates for our analyses come from the Bureau of the Census, Current Population Survey, Outgoing Rotation Groups files from 1983 through 2002. Wages are inflated to 2005 dollars using the CPI-U-RS. Workers' hourly wage rates are either (i) the reported hourly wage (for the 60 percent of workers 
paid on that basis) or (ii) weekly earnings divided by weekly hours (for the other 40 percent of workers). ${ }^{11}$ To avoid measurement error from using wages derived from salary and "usual" hours data, we drop the latter group of workers for our primary analysis. ${ }^{12}$ The focus of our investigation is therefore on "hourly" workers. This group has received much of the attention in previous VSL studies. [Viscusi and Aldy (2003)]

Table 3 summarizes the data describing hourly workers. In particular, the table reports means for attributes of men and women, broken down according to whether the individual works in a high or low risk occupation. ${ }^{13}$ There are a few interesting points that can be made simply by looking at these raw data. Men in high risk occupations earn more on average than those in low risk occupations, even though the latter are more likely to be college educated. This suggests the sort of variation in the data that would yield a positive VSL. Men in high risk occupations are, however, also more likely to be older, married, union members, fulltime workers, and white - all of which are factors that would likely contribute to their being paid a higher wage. This highlights the importance of controlling for individual heterogeneity when applying our estimators. We describe how this is done in the following section.

Unlike their male counterparts, women in high risk occupations tend to earn lower wages. Like men, women with any college training are less likely to work in those jobs. Across most other attributes, women are similar irrespective of whether they work in a

\footnotetext{
${ }^{11}$ Imputed data on wage rates were used to describe some hourly workers. In cases where individuals do not provide complete responses to the Census Bureau interviewers, the Census Bureau imputes the missing data using the information provided by a different respondent with some of the same characteristics, when those characteristics were likely to be associated with the missing data.

${ }^{12}$ In Section 6.2, we do report a separate set of results for salaried workers.

${ }^{13}$ The individual is considered to be in a high risk occupation if that occupation has fatality risk above the median risk across all 43 occupations (i.e., 1.571 deaths per 100,000 workers each year).
} 
high or low risk occupation. Finally, note that $83 \%$ of men work in occupations classified as high risk, while only $35 \%$ of women do so.

\section{ESTIMATION STRATEGY 1: IDENTIFICATION}

We begin by describing our identification strategy with a simple model of sorting by individuals into one of two occupations $(j=1,2)$. We indicate the wage earned by individual $i$ should he choose to work in occupation \#1 or \#2 as $\omega_{i, 1}$ and $\omega_{i, 2}$, respectively. In contrast to the classic Roy model, where sorting across occupations is driven entirely by an individual's pecuniary compensation, we model sorting as determined by his wage draw in each occupation and by non-wage determinants of utility specific to each particular occupation. We summarize the latter (for now) as "tastes". The conventional wisdom is that there is no additional information in conditional wage distributions with which to identify these taste parameters. In the following model, we show how they are, in fact, identified with the help of a simple assumption.

We begin by modeling individual $i$ 's utility from choosing occupation $j$ as the sum of wages $\left(\omega_{i, j}\right)$ and tastes $\left(\tau_{j}\right)$ :

$$
U_{i, j}=\omega_{i, j}+\tau_{j}
$$

The first important restriction we impose on the model is that there is no idiosyncratic component to the taste parameter (i.e., we estimate $\tau_{j}$ instead of $\left.\tau_{i, j}\right) .{ }^{14}$ After first

\footnotetext{
${ }^{14}$ By estimating this model separately for different types of individuals, it is possible to allow the taste to vary with observable individual attributes. However, allowing tastes to vary with unobservable individual attributes does not appear to be possible without relying on strict distributional assumptions. Our goal is to demonstrate how identification can be achieved without resorting to such distributional assumptions.
} 
explaining how to recover estimates of these taste parameters, we describe how they can be used to recover the value workers place on particular non-pecuniary occupation attributes (e.g., fatality risk).

Without loss of generality, we normalize $\tau_{1}=0 .{ }^{15}$ At this point, the goal of our exercise is to recover an estimate of $\tau_{2}{ }^{16}$ The difficulty in doing so arises from the fact that we only see (i) wage distributions conditional upon optimal sorting behavior, and (ii) an indicator of which occupation an individual chooses. In particular, for an individual $i$, we only observe $\omega_{i, 2}$ if:

$$
\omega_{i, 2}+\tau_{2} \geq \omega_{i, 1}
$$

Alternatively, we only observe $\omega_{i, 1}$ if:

$$
\omega_{i, 2}+\tau_{2}<\omega_{i, 1}
$$

Denote the smallest wage (i.e., the minimum order statistic, or extreme quantile) that we observe from someone choosing occupation $\# 1$ or $\# 2$ by $\underline{w}_{1}$ and $\underline{w}_{2}$, respectively. Assuming that the unconditional distributions of $\omega_{1}$ and $\omega_{2}$ have finite lower points of supports (denoted by $\omega_{1}^{*}$ and $\omega_{2}^{*}$ ), we know the smallest value of $\omega_{1}$ that we could ever see, given that individuals maximize utility:

\footnotetext{
${ }^{15}$ As in all random-utility frameworks, utility is only identified up to an additive constant. This requires some sort of a normalization, which we use to eliminate one of the $\tau$ 's from the two-occupation example. In the more general $\mathrm{N}$ occupation case, we estimate $(\mathrm{N}-1)$ distinct $\tau$ 's.

${ }^{16}$ Bayer, Khan, and Timmins (2007) describe how non-parametric estimates of the unconditional wage distributions can be recovered as well.
} 


$$
\begin{array}{lll}
\underline{w}_{1}=\omega_{1}^{*} & \text { if } & \omega_{1}^{*}>\omega_{2}^{*}+\tau_{2} \\
\underline{w}_{1}=\omega_{2}^{*}+\tau_{2} & \text { if } & \omega_{1}^{*} \leq \omega_{2}^{*}+\tau_{2}
\end{array}
$$

Similarly, the smallest value of $\omega_{2}$ that we could ever observe would be:

$$
\begin{array}{lll}
\underline{w}_{2}=\omega_{2}^{*} & \text { if } & \omega_{1}^{*} \leq \omega_{2}^{*}+\tau_{2} \\
\underline{w}_{2}=\omega_{1}^{*}-\tau_{2} & \text { if } & \omega_{1}^{*}>\omega_{2}^{*}+\tau_{2}
\end{array}
$$

In order to make sense of (10) and (11), define the following two cases:

$$
\begin{array}{ll}
A: & \omega_{1}^{*}>\omega_{2}^{*}+\tau_{2} \\
B: & \omega_{1}^{*} \leq \omega_{2}^{*}+\tau_{2}
\end{array}
$$

We are not able to tell whether case A or B prevails in the data without first recovering an estimate of $\tau_{2}$, which is the object of the estimation procedure. Conveniently, we are able to recover an estimate of $\tau_{2}$ in either case. ${ }^{17}$ In particular:

$$
\tau_{2}=\underline{w}_{1}-\underline{w}_{2}
$$

Equation (13) therefore describes our minimum order statistic estimator for $\tau_{2}$ in the simplest two-occupation case. Figures 7 and 8 illustrate the intuition underlying this

\footnotetext{
${ }^{17}$ By exploiting information contained in the extreme tails of the wage distribution, this approach has much in common with the "identification at infinity" strategy for estimating treatment effects under selection described in Heckman (1990).
} 
estimator for cases A and B, respectively. The heavy dashed lines in each figure correspond to the minimum order statistics that would be observed in the data (i.e., $\underline{w}_{1}=\omega_{1}^{*}$ and $\underline{w}_{2}=\omega_{1}^{*}-\tau_{2}$ in case $\mathrm{A}$, and $\underline{w}_{1}=\omega_{2}^{*}+\tau_{2}$ and $\underline{w}_{2}=\omega_{2}^{*}$ in case B). In each case, the difference between the heavy dashed lines identifies $\tau_{2}$.

We reiterate at this point that, at no point in the preceding discussion were we required to say anything about the relative sizes of the variances of wage draws across occupations or the correlation in an individual's wage draws across occupations. Correlations that are positive, negative, or zero are all consistent with this model. Identification relies only on differences in the supports of different conditional wage distributions.

The theory used to describe the simple two-occupation case scales-up naturally to any number of potential occupations. With more than two potential occupations, however, we require some additional notation. Consider the following three-occupation system with wages for individual $i$ denoted by $\omega_{1, i}, \omega_{2, i}$, and $\omega_{3, i}$. We denote the lower supports of each occupation's wage distribution by $\omega_{1}^{*}, \omega_{2}^{*}$, and $\omega_{3}^{*}$. We therefore normalize $\tau_{1}=0$. For individual $i$, we observe $w_{i}$, where:

$$
\begin{array}{r}
w_{i}=\omega_{1, i} I\left[\omega_{1, i}>\max \left(\omega_{2, i}+\tau_{2}, \omega_{3, i}+\tau_{3}\right)\right]+ \\
\omega_{2, i} I\left[\omega_{2, i}+\tau_{2}>\max \left(\omega_{1, i}, \omega_{3, i}+\tau_{3}\right)\right]+ \\
\omega_{3, i} I\left[\omega_{3, i}+\tau_{3}>\max \left(\omega_{1, i}, \omega_{2, i}+\tau_{2}\right)\right]
\end{array}
$$

We also observe an indicator corresponding to which occupation individual $i$ has selected - i.e., $d_{1, i}, d_{2, i}$, and $d_{3, i}$. We note that, under convex supports for all random variables and 
assuming finite lower support points $\left(\omega_{1}^{*}, \omega_{2}^{*}, \omega_{3}^{*}\right)$, we have the following conditional minimum order statistics:

$$
\begin{aligned}
& \underline{w}_{1}=\min \left(w_{i} \mid d_{1, i}=1\right)=\max \left(\omega_{1}^{*}, \omega_{2}^{*}+\tau_{2}, \omega_{3}^{*}+\tau_{3}\right) \\
& \underline{w}_{2}=\min \left(w_{i} \mid d_{2, i}=1\right)=\max \left(\omega_{1}^{*}, \omega_{2}^{*}+\tau_{2}, \omega_{3}^{*}+\tau_{3}\right)-\tau_{2} \\
& \underline{w}_{3}=\min \left(w_{i} \mid d_{3, i}=1\right)=\max \left(\omega_{1}^{*}, \omega_{2}^{*}+\tau_{2}, \omega_{3}^{*}+\tau_{3}\right)-\tau_{3}
\end{aligned}
$$

Notice that $\tau_{3}$ is equal to $\left(\underline{w}_{1}-\underline{w}_{3}\right)$, while $\tau_{2}$ is equal to $\left(\underline{w}_{1}-\underline{w}_{2}\right)$.

With estimates of $\tau$ for multiple occupations $j=1,2, \ldots$, it becomes possible to decompose the taste parameter into the utility effects of multiple non-pecuniary occupation characteristics, $X$ (including fatality risk), along with an unobserved occupation attribute, $\varepsilon_{j}$, by way of regression analysis. ${ }^{18}$

$$
\tau_{j}=X_{j}^{\prime} \beta+\varepsilon_{j}
$$

\section{ESTIMATION STRATEGY 1: RESULTS}

In this section, we describe the results of two sets of estimation procedures. The first is based on the traditional wage-hedonic model for recovering marginal willingnessto-pay for reductions in fatality risk. In particular, we estimate a regression of the form:

\footnotetext{
${ }^{18}$ This assumes, of course, that $\mathrm{E}[\varepsilon X]=0$, which may be violated if there are important omitted job characteristics. In our application, we deal with this concern directly by employing the best available data describing occupation attributes. Alternatively, if one believed that correlated unobservable job attributes were time invariant, and if one could exploit time variation in fatality risk, it would be possible to estimate multiple taste parameters (i.e., a different vector for each time period), pool them over time, and include occupation fixed effects in equation (16) to deal with the endogeneity. See, for example, the data used by Costa and Kahn (2004) in their analysis of changes in the VSL from 1940-1980.
} 


$$
w_{i, j}=\alpha_{0}+Z_{i}^{\prime} \alpha_{1}+\alpha_{2} \text { FATAL }_{j}+X_{j}^{\prime} \alpha_{3}+\varepsilon_{i, j}
$$

where $i$ indexes workers and $j$ indexes forty-three occupation categories. ${ }^{19} Z$ is a vector of variables describing worker $i$ including:

$\begin{array}{ll}\text { HSDROP } & \text { worker is a high-school dropout } \\ \text { HSGRAD } & \text { worker is a high-school graduate } \\ \text { SOMECOLL } & \text { worker has completed < } 4 \text { years of college } \\ \text { COLLGRAD } & \text { worker has a four year college degree } \\ \text { AGE } & \text { age measured in years } \\ \text { AGE2 } & \text { age-squared } \\ \text { MARRIED } & \text { worker is married and lives with spouse } \\ \text { UNION } & \text { worker is a union member } \\ \text { MSA } & \text { worker lives in a metropolitan area } \\ \text { FULLTIME } & \text { fulltime worker (i.e., hours }>35 \text { per week) } \\ \text { PUBLIC } & \text { worker is in the public sector } \\ \text { BLACK } & \text { worker is African-American } \\ \text { OTHER } & \text { worker is other race (non-white) } \\ \text { HISPANIC } & \text { worker is of Hispanic decent } \\ \text { NEW ENGLAND } & \text { worker lives in New England census region } \\ \text { MID-ATLANTIC } & \text { worker lives in Mid-Atlantic census region } \\ \text { EAST NORTH CENTRAL } & \text { worker lives in East North Central census region } \\ \text { WEST NORTH CENTRAL } & \text { worker lives in West North Central census region } \\ \text { SOUTH ATLANTIC } & \text { worker lives in South Atlantic census region } \\ \text { EAST SOUTH CENTRAL } & \text { worker lives in East South Central census region } \\ \text { WEST SOUTH CENTRAL } & \text { worker lives in West South Central census region } \\ \text { MOUNTAIN } & \text { worker lives in Mountain census region } \\ \text { PACIFIC } & \text { worker lives in Pacific census region } \\ & \end{array}$

$X$ is a vector of non-pecuniary occupation attributes other than fatality risk. These include:

\footnotetext{
${ }^{19}$ We also estimated a set of traditional wage-hedonic specifications using the natural log of hourly wages as the dependent variable. These specifications yield a statistically significant and positive relationship between fatal risk and male wages and a statistically significant, but negative relationship between fatal risk and female wages.
} 
NONFATAL "Anticipated" days of work lost due to nonfatal injury.

SCMPLX Substantive complexity, including complexity of function in relation to data, general educational development, intelligence, numerical aptitude, adaptability to performing repetitive work, sensor or judgmental criteria, specific vocational preparation, and verbal aptitude.

MSKILL Motor skills, including color discrimination, finger dexterity, manual dexterity, motor coordination, and complexity in relation to things.

PHYDDS Physical demands, including climbing and balancing, eye-handfoot coordination, dealing with hazardous conditions or outside working conditions, stooping, kneeling, crouching, or crawling.

WORCON Working conditions, including extreme cold, extreme heat, wetness, or humidity.

CSKILL Creative skills, including abstract and creative activities, feelings, ideas, or facts.

INTPEOPLE Worker interactions with people.

The main variable of interest is the fatality risk associated with occupation $j$, represented by FATAL (the number of deaths per 100 full-time workers) which we defined above.

Recognizing that the value placed on certain job attributes may differ with worker attributes, we also estimate a regression of the form:

$$
w_{i, j}=\alpha_{0}+Z_{i}^{\prime} \alpha_{1}+\alpha_{2} \text { FATAL }_{j}+X_{j}^{\prime} \alpha_{3}+\left(X_{j} d_{\text {coll }}\right)^{\prime} \alpha_{4}+\left(X_{j} d_{A G E>40}\right)^{\prime} \alpha_{5}+\varepsilon_{i, j}
$$

where $d_{\text {coll }}$ is a dummy variable indicating that SOMECOLL $=1$ or COLLGRAD $=1$, and $d_{A G E>40}$ is a dummy variable indicating that the individual is over 40 years of age. At this stage of the analysis, we restrict our estimate of the compensating differential in wages (and, hence, the VSL) to be constant across worker attributes. 
We then take the estimate of the marginal willingness-to-pay to avoid fatality risk, $\alpha_{2}$, and scale this up by a typical number of hours worked in a year $(2,000)$ and by the number of workers over whom the annual fatality risk was measured (100). This provides us with our estimated VSL.

Table $4 \mathrm{a}$ describes the results of regression equations (17) and (18) for both men and women where the dependent variable is the hourly wage. Table $4 \mathrm{~b}$ describes the corresponding results where the dependent variable is the log hourly wage. In each case, we estimate two specifications - one in which we use worker-occupation attribute interactions, and another in which we do not. All results reported in this section of the paper are based on a trimmed sample that drops all individuals reporting wages lower than the federally mandated minimum wage in the year of observation. ${ }^{20,} 2195$ percent confidence intervals, which were calculated allowing for clustering at the occupation level, were computed using an $\mathrm{M} / \mathrm{N}$ bootstrap method.

\subsection{Minimum Order Statistic Estimator}

We carry-out a comparable set of specifications of our minimum order statistic estimator. The practical difficulty in applying this estimator in the current context arises in controlling for the rich set of worker attributes provided by the CPS. One alternative is to divide the data up into very small groups and apply the estimator non-parametrically to each group. An advantage of doing so would be that we would be able to estimate taste

\footnotetext{
${ }^{20}$ In many years, CPS wages are top-coded at a nominal value of $\$ 99.99$. We drop all observations nominally at or above this top-coded value in every year. Dropping observations with wages below the federally mandated minimum wage reduces the influence of mismeasured wages, particularly in the lower tail of the wage distribution. Results without lower trimming are reported in the sub-section 6.2.

${ }^{21} \mathrm{Keep}$ in mind that, in the traditional wage-hedonic model, a disamenity enters the wage equation positively, indicating a positive wage differential paid to compensate for the unattractive job attribute.
} 
parameters that vary with observable individual attributes. The problem that arises, however, is that for a particular group (e.g., black, non-Hispanic, married men aged 18-30 with a high-school education, living in an MSA in New England, who are fulltime workers but not in the public sector), we may be unlikely to see many individuals in a particular occupation (e.g., machine operators). The estimator becomes very sensitive to the wages of the few individuals we do see, and fails if we see no workers in a group. Alternatively, we could choose not to control for individual attributes at all, but then we would be deriving our measure of the VSL from the wages and occupation choices of a potentially unrepresentative group. We therefore adopt a two-stage estimation procedure that introduces some parametric modeling. ${ }^{22}$ We first estimate a regression of the form:

$$
\hat{w}_{i, j}=\beta_{0}+Z_{i}^{\prime} \beta_{1}+u_{i, j}
$$

where $\hat{w}_{i, j}$ is individual $i$ 's observed wage in occupation $j$, having differenced out the mean of all wages earned by workers in occupation $j$. $\xi_{i, j}$ measures worker $i$ 's wage in occupation $j$, purged of the effects of observable individual attributes $Z_{i}:^{23}$

$$
\xi_{i, j}=w_{i, j}-\beta_{0}-Z_{i}^{\prime} \beta_{1}
$$

\footnotetext{
22 This two-step approach is similar to that employed by Bajari and Kahn (2005), who face a similar problem of needing to perform non-parametric estimation with an abundance of covariates.

${ }^{23}$ Note that we use $w_{i, j}$, not $\hat{w}_{i, j}$, in deriving $\xi_{i, j} . \xi_{i, j}$ should be purged of the effects of observable individual attributes, but not of the level-effects attributable to being in different occupations.
} 
We then use $\xi_{i, j}$ as our "wage" in implementing the lower bound estimator. This allows us to compare different individuals without having to divide them into unreasonably small sub-groups. ${ }^{24}$

In particular, normalizing the taste parameter for a large occupation (i.e., occupation \#34 - construction trades) to be zero, we recover estimates of the taste parameters for the remaining sectors according to the formula:

$$
\tau_{j}=\underline{\xi}_{34}-\underline{\xi}_{j}
$$

and carry out the second-stage regression to recover the value of non-pecuniary job attributes:

$$
\tau_{j}=\theta+\beta_{2} F A T A L_{j}+X_{j}^{\prime} \beta_{3}+v_{j}
$$

where $\theta$ accounts for the arbitrary choice of normalization in deriving the $\tau$ 's. In a final specification, we also include interactions between $X_{j}$ and $d_{\text {coll }}$ and between $X_{j}$ and $d_{A G E>40}$ in the estimation of equation (19).

We rely on $\mathrm{M} / \mathrm{N}$ bootstrapping techniques to recover confidence intervals. ${ }^{25}$ In particular, we conduct $1000 \mathrm{M} / \mathrm{N}$ bootstrap simulations of each specification, from which

\footnotetext{
${ }^{24}$ This assumption does impose the constraint that job attributes and worker characteristics enter additively in determining a worker's wage. This is restrictive, but not significantly different from the assumption usually maintained in the VSL literature. We have also estimated specifications that relax this assumption as well as specifications that allow the effect of worker characteristics to vary by occupation. These specifications, available upon request, yield minimum order statistics that are very similar to those obtained from the specification presented in this paper.

${ }^{25}$ Inference is complicated by the fact that the lower bound estimator does not have an asymptotically normal distribution. The traditional bootstrap algorithm, moreover, is invalid when the estimate is not
} 
we derive symmetric $95 \%$ confidence intervals. ${ }^{26}$ Results are consistent with expectations - workers exhibit a strong and statistically significant disutility from increased fatality risk. $^{27}$

One might reasonably be concerned with the effect of measurement error and outliers on the performance of this estimator. Put simply, if the differences between minimum order statistics are driven by outliers or mismeasured data, this will filter through the model and drive our point estimate of the marginal utility associated with each job attribute. We take comfort, however, from the fact that our estimates are nearly always statistically significant. If our estimates were, in fact, being driven by outliers or many forms of measurement error, we would expect this to be reflected in large standard errors calculated by our bootstrap procedure. ${ }^{28}$

Tables 5 and 6 report the results of our minimum-order-statistic estimator, for both men and women. The first and third columns refer to the specification that does not include worker-occupation attribute interactions; the second and fourth columns include these interactions. Tables $5 \mathrm{a}$ and $5 \mathrm{~b}$ report results where the dependent variable was the hourly wage while Tables $6 \mathrm{a}$ and $6 \mathrm{~b}$ report results where the dependent variable was the log hourly wage. Tables 5a and 6a reports results for equation (19), while Tables 5b and

asymptotically normal. This problem is overcome by the use of the M/N bootstrap, a variant on subsampling (here, we use bootstrapped sub-samples that are $1 / 4$ the size of the full data set). While yielding inefficient (i.e., overly large) estimates of the confidence interval, the $\mathrm{M} / \mathrm{N}$ bootstrap does produce confidence interval estimates that are consistent.

${ }^{26}$ Specifically, a bootstrap simulation consists of taking a random $1 / 4$ sub-sample (drawn with replacement) from the population of $\xi_{i, j}$ 's. We then determine the values of $\tau_{j}, j=1,2, \ldots, 43$, and regress these values on the vector of occupation attributes. We record the resulting estimates and repeat the entire process 1000 times. The bootstrapped confidence interval is then found by taking the $2.5^{\text {th }}$ and $97.5^{\text {th }}$ percentiles of the distribution of bootstrapped parameter estimates.

${ }^{27}$ In contrast to the traditional wage-hedonic model, we are here estimating structural utility function parameters. Disutility is therefore indicated by a negative parameter value. Recall, moreover, that these parameter estimates are already normalized by the marginal utility of wages, so that they can be interpreted as marginal willingnesses-to-pay, and are comparable across sub-populations.

${ }^{28}$ That is, any particular M/N sample would be unlikely to contain the problematic observation, producing a very different point estimate. 
$6 \mathrm{~b}$ reports the results of equation (22). Also reported are $95 \%$ confidence intervals derived from the $\mathrm{M} / \mathrm{N}$ bootstrap.

Table 7a summarizes the VSL estimates from both the traditional wage hedonic and minimum order statistic estimation techniques for each of the specifications described above when the dependent variable wage the hourly wage. Looking only at point estimates for men, the minimum order statistic estimator produces VSL estimates that are 2.7 and 4.3 times greater than those produced by the traditional wage hedonic procedure. The minimum order statistic estimates are, moreover, statistically significant with a $95 \%$ confidence interval ranging from approximately $\$ 5$ million to almost $\$ 16$ million.

For women, the difference between the two models is even starker. The minimum order statistic estimator yields results that are similar to those for men $-\$ 7.95$ or $\$ 11.76$ million, depending upon whether worker-occupation attribute interactions are included in the first-stage estimation. Moreover, these results are statistically significant. By contrast, the wage-hedonic procedure yields negative VSL point estimates for women. In all cases, we can reject the hypothesis that the VSLs estimated by traditional wagehedonic methods are equal to those estimated from minimum order statistics.

The log-wage hedonic specification (see Table 7b) yields estimates of the VSL for men that are even lower (approximately $\$ 1.02$ to $\$ 1.75$ million) and yields estimates of the VSL for women that are also negative (approximately $-\$ 8.59$ million). The minimum order statistic estimates of the VSL are larger for men (between \$9 and \$10 million) and positive for women (between $\$ 3.7$ and $\$ 7.5$ million). Again, we can reject the hypothesis that the VSLs estimated by traditional wage-hedonic methods are equal to those estimated from minimum order statistics. 


\subsection{Alternative Specifications}

Because our estimator is based on the minimum order statistic, it is possible that our results may be sensitive to the particular choice of model specification (including the criteria used to draw a data sample). In this sub-section, we explore that sensitivity with a variety of alternative specifications. Tables $8 \mathrm{a}$ and $8 \mathrm{~b}$ report the VSL estimates arising from twelve alternatives. We note at the outset that in these subsamples, the traditional wage-hedonic procedure typically does not produce a statistically significant estimate, and for women, most of the point-estimates have the wrong sign. Table 8a reports the results from the hourly wage specifications while Table $8 \mathrm{~b}$ reports the results from the log hourly wage specifications. The first row of Table 8a reports estimates based on the sample of salaried workers. Minimum order statistic estimates remain significant, but fall relative to their values for wage workers (more so for men than for women). Wagehedonic estimates, on the other hand, rise dramatically but have large confidence intervals. The second row reports results based on a sample of hourly workers that does not drop those reporting wages below the federally mandated minimum. These low wages may be real observations, but might also simply reflect measurement error. Including these low wages has the effect of collapsing across-occupation variation at the bottom of the wage distribution, with the effect of reducing the VSL estimate based on the minimum order statistic. Even with this reduction, however, the estimate is still statistically significant and larger than that based on the traditional wage hedonic technique. 
The next four rows describe results based on samples drawn to include only individuals in a certain age range. ${ }^{29,30}$ In particular, we perform the exact same estimation procedure described in the previous sub-section (including estimating parameters on AGE and AGE2), but do so only on a sub-set of workers (e.g., aged 20 to 29). It is reassuring that the same inverted-U pattern found in previous work is apparent in our results. The inverted-U is, moreover, shifted upward for the minimum order statistic estimates relative to the wage-hedonic estimates.

The next two rows describe how the VSL varies with marital status. Using the minimum order statistic estimator, we find that married men have a higher VSL. This difference goes away when considering women, and is not present for men or women when using the traditional wage-hedonic estimator.

The next two rows describe how the VSL estimates vary with the time period of analysis. If we restrict our data to the 1983 to 1992 period, we obtain larger estimates for men of the VSL based on minimum order statistics while if we restrict the data to the 1993 to 2002 period, we get smaller estimates for men. For women, the estimates of the VSL based on minimum order statistics are, by contrast, larger in the latter period.

The final two rows of Tables $8 \mathrm{a}$ and $8 \mathrm{~b}$ illustrate two cases in which our model may not perform well. In the first, we restrict ourselves to using a limited set of worker attributes (AGE, AGE2, HSDROP, SOMECOLL, COLLGRAD). This has the effect of reducing the variability across occupations in the lower bound of our wage distributions. ${ }^{31}$

\footnotetext{
${ }^{29}$ In these results (and in the remainder of the results in this section), we use the trimmed sample of hourly workers as a starting point.

${ }^{30}$ Besides age, researchers have also calculated VSLs that differ with respect to race [Viscusi (2003)], income, and union status [summarized in Viscusi and Aldy (2003)].

${ }^{31}$ Consider an extreme example. When we trim all observations below the federally mandated minimum wage and use no covariates, it will likely be the case that there is no variation at all across sectors in the
} 
The result is to provide a sort of lower bound on the VSL estimate. While the minimum order statistic estimate falls below that found with the wage-hedonic model, it does remain statistically significant. This result highlights the importance of explaining as much of the variation in wages as possible with observable worker attributes.

The final row illustrates the effects of having little cross-occupation variation in fatality risk. In particular, we eliminate the relatively risky occupation categories \#41 \#43 (i.e., farm managers, farm workers, and forestry \& fishing). The result is to increase the confidence intervals for the estimates derived from both techniques (particularly for the minimum order statistic estimator). The change has little effect on the point estimate for men based on the wage-hedonic technique, but the point estimate based on the minimum order statistic jumps dramatically.

\section{ESTIMATION STRATEGY 2}

While the CPS provides high-quality data on wages, one might generally be concerned about the potential for measurement error or outliers to prevent us from accurately measuring the true minimum order statistic. A similar concern might arise in settings where one has a relatively small sample to work with. In this section, we employ an alternative estimation strategy that instead uses data from the entire conditional wage distribution and makes no assumption about the distributions' supports. [Bayer, Khan, and Timmins (2007)] Instead, it relies upon two alternative identifying assumptions: (i)

lower point of support. The VSL recovered with our minimum order statistic estimator would therefore be $\$ 0$. 
the unconditional distribution of log-wage in occupation $j$ is normal with mean $\mu_{j}$ and variance $\sigma_{j}^{2}$, and (ii) wage draws for individual $i$ are independent across occupations. ${ }^{32}$

To explain this estimator, we return to the simple model of individuals sorting over two occupations, indexed by \#1 and \#2. Without loss of generality, we again normalize the taste for occupation \#1 to zero $\left(\tau_{1}=0\right)$. We define a variable $d_{i}$, which functions as an indicator that individual $i$ chose occupation \#1:

$$
d_{i}=I\left[\omega_{1, i}>\omega_{2, i}+\tau_{2}\right]
$$

Using this indicator, we can write down an expression for individual $i$ 's observed wage:

$$
w_{i}=d_{i} \omega_{1, i}+\left(1-d_{i}\right) \omega_{2, i}
$$

i.e., the individual receives his draw from occupation \#1 if it was utility maximizing to choose that occupation. Next, define the following joint probability distributions, both of which are easily observed in the data:

$$
\Psi_{1}(t)=P\left(d_{i}=1, w_{i} \leq t\right) \quad \Psi_{2}(t)=P\left(d_{i}=0, w_{i} \leq t\right)
$$

We will also work with the derivatives of these expressions, denoted by:

\footnotetext{
32 This same assumption underlies the traditional wage-hedonic model estimated with cross-sectional data (with panel data, individual fixed effects have been used to control for unobserved worker productivity). With panel data, we could relax the independence assumption in our model as well, as we could include individual fixed effects amongst the individual characteristics in the estimation of equation (19).
} 


$$
\psi_{1}(t)=\frac{\partial}{\partial t} P\left(d_{i}=1, w_{i} \leq t\right) \quad \psi_{2}(t)=\frac{\partial}{\partial t} P\left(d_{i}=0, w_{i} \leq t\right)
$$

Focusing on the expression for $\Psi_{l}(t)$, we exploit the assumption that wage draws (conditional on observable individual attributes) are independent across sectors to re-write it as follows:

$$
\begin{aligned}
\Psi_{1}(t) & =P\left(d_{i}=1, w_{i} \leq t\right) \\
& =P\left(\omega_{1, i}>\omega_{2, i}+\tau_{2}, \omega_{1, i} \leq t\right)=P\left(\omega_{1, i}-\tau_{2}>\omega_{2, i}, \omega_{1, i} \leq t\right) \\
& =\int_{-\infty}^{t} f_{1}\left(\omega_{1}\right) d \omega_{1} \int_{-\infty}^{\omega_{1}-\tau_{2}} f_{2}\left(\omega_{2}\right) d \omega_{2}=\int_{-\infty}^{t} f_{1}\left(\omega_{1}\right) F_{2}\left(\omega_{1}-\tau_{2}\right) d \omega_{1}
\end{aligned}
$$

This means that we can define $\psi_{l}(t)$ as:

$$
\psi_{1}(t)=\frac{\partial}{\partial t} \int_{-\infty}^{t} f_{1}\left(\omega_{1}\right) F_{2}\left(\omega_{1}-\tau_{2}\right) d \omega_{1}=f_{1}(t) F_{2}\left(t-\tau_{2}\right)
$$

An analogous argument defines $\psi_{2}(t)$ :

$$
\psi_{2}(t)=\frac{\partial}{\partial t} \int_{-\infty}^{t} f_{2}\left(\omega_{2}\right) F_{1}\left(\omega_{2}+\tau_{2}\right) d \omega_{2}=f_{2}(t) F_{1}\left(t+\tau_{2}\right)
$$


Going back to the final integral in equation (27) and carrying out integration-by-parts yields:

$$
\Psi_{1}(t)=\int_{-\infty}^{t} f_{1}\left(\omega_{1}\right) F_{2}\left(\omega_{1}-\tau_{2}\right) d \omega_{1}=F_{1}(t) F_{2}\left(t-\tau_{2}\right)-\int_{-\infty}^{t} F_{1}(s) f_{2}\left(s-\tau_{2}\right) d s
$$

Performing a change of variables $u=s-\tau_{2}$, equation (30) becomes:

(31) $\quad \Psi_{1}(t)=F_{1}(t) F_{2}\left(t-\tau_{2}\right)-\int_{-\infty}^{t-\tau_{2}} F_{1}\left(u+\tau_{2}\right) f_{2}(u) d u$

Next, we use the expressions for $\psi_{1}(t)$ and $\psi_{2}(t)$ defined in (28) and (29) to re-write equation (31) as follows:

$$
\Psi_{1}(t)=\frac{F_{1}(t) \psi_{1}(t)}{f_{1}(t)}-\int_{-\infty}^{t-\tau_{2}} \psi_{2}(u) d u
$$

Noting that the integral term in (32) is simply $\Psi_{2}\left(t-\tau_{2}\right)$, we can solve for the distribution of $\omega_{1}$ as a function of $\tau_{2}$ :

$$
\lambda_{1}(t)=\frac{f_{1}(t)}{F_{1}(t)}=\frac{\psi_{1}(t)}{\Psi_{1}(t)+\Psi_{2}\left(t-\tau_{2}\right)}
$$


where $\lambda_{1}(t)$ is a function of the unconditional wage distribution in location \#1. (33) is a single equation in two unknowns $\left(\lambda_{1}(t)\right.$ and $\left.\tau_{2}\right)$ when evaluated at a particular value of $t$, and it is therefore not surprising that we cannot identify both of these values without making an additional assumption. Bayer, Khan, and Timmins (2007) show how the equation can be estimated without parametric assumptions in a model of spatial sorting by assuming that workers living in the same location receive a wage draw from the same distribution irrespective of where they migrated from. That source of variation is not available in the data used to recover the VSL. Instead, we make a parametric assumption about $\mathrm{F}_{1}(t)$. Assuming $\mathrm{F}_{1}(t)$ is the cumulative normal distribution with mean $\mu_{1}$ and variance $\sigma_{l}^{2}$ would reduce equation (33) to three parameters. The number of parameters does not increase, moreover, as we consider the expression evaluated at different values of $t$. By forcing the equation to hold for many values of $t$, we therefore have more equations than unknowns and can easily identify the model's parameters.

The preceding arguments scale-up to any number of occupations (although the denominator in the right-hand-side expression of (33) becomes more complicated). We can, therefore, estimate the model in our occupational sorting context by forming a minimum-distance criterion function based on equation (33). In our application, minimizing this objective function requires us to search over a high-dimensional parameter space (i.e., forty-three means, forty-three variances, and forty-two taste parameters, which could then be regressed on job attributes as in equation (16)). ${ }^{33} \mathrm{We}$ make one further simplifying assumption in order to facilitate estimation - that the taste parameter can be written as a function of observable occupation attributes: $\tau_{j}=X_{j}^{\prime} \beta$.

\footnotetext{
${ }^{33}$ In this unrestricted specification, one of the taste parameters must still be normalized to zero.
} 
We therefore need to only estimate eight $\beta$ parameters instead of a separate $\tau_{j}$ for each occupation.

Table 9 describes the outcome of this estimation procedure applied to the sample of male hourly workers earning more than the federal minimum wage. ${ }^{34}$ We evaluate a minimum distance criterion function based on (33) at 200 values of log-wages evenly spaced between 0.25 and $4.25 .^{35}$ Standard errors are bootstrapped from 800 re-samples. Because we are modeling log-wages, the coefficient on fatality risk needs to be multiplied by the wage rate before being converted into a VSL. We use the average wage rate in the sample (\$13.16). The result is a statistically significant VSL estimate of $\$ 8.05$ million, which is smaller than that recovered by our first estimator, but more than four times larger than the comparable estimate from the wage-hedonic model in Table $7 \mathrm{~b}$ (i.e., $\$ 1.756$ million).

Although the assumptions and methodology used to arrive at this estimate differ dramatically from those in the previous section, the result is remarkably similar. Controlling for Roy sorting, we recover a VSL that is three to four times greater than that derived from traditional wage-hedonics. Taken together, the results of these two methodological approaches lead us to conclude that the VSL based on traditional wagehedonic techniques is indeed biased downward by Roy sorting.

\footnotetext{
${ }^{34}$ Specifically, we apply the procedure to the "purged" wage data that were created by removing the variation in wages explained by observable worker attributes (i.e., $\xi_{i, j}$ from equation (20)).

${ }^{35}$ Bayer, Khan, and Timmins (2007) describe the details of this procedure. For example, we use normal density kernels and a Silverman's rule of thumb to approximate $\psi_{j}(t) . \Psi_{j}(t)$ is measured nonparametrically as a step-function.
} 


\section{CONCLUSIONS}

The effect of individual unobservable heterogeneity (i.e., productivity) on estimates of the value of a statistical life has been addressed in previous work, but occupational (Roy) sorting based on idiosyncratic returns is absent from the literature on VSL. We demonstrate that this type of sorting has the potential to bias wage-hedonic estimates of the VSL. Recovering the size and direction of that bias is a difficult empirical problem that depends partly upon the relative variances of the unconditional sector-specific wage distributions.

We first demonstrate a way to deal with Roy sorting bias without recovering the unconditional wage distributions and without relying upon distributional assumptions. Doing so requires the relatively innocuous assumption that wage distributions have finite lower bounds. In addition to controlling for the biases induced by Roy sorting, this nonparametric estimator also corrects for biases resulting from unobserved productivity, of the sort described by Hwang et al (1992). It is, moreover, easy to use - everything (except standard errors) can be calculated with a spreadsheet. Finally, it can be expanded to use better data sets (e.g., a finer gradation of occupation/sector, like those used by Kniesner et al (2006) or Scotten and Taylor (2007). In so doing, however, it does also require the strong practical assumption that we can accurately measure the minimum order statistic associated with conditional wage distribution. For some (small, noisy) data sets, this will clearly not be the case. In response to this concern, we offer a second estimation strategy that does not impose strict data requirements but that does require an independence assumption on wage draws when using cross-sectional data. The conclusions of both models are that traditional wage-hedonic techniques yield 
significantly downwardly biased estimates of the VSL. That bias is big enough, moreover, to matter for policy. Estimates for men rise by a factor of three or more while estimates for women become positive and of similar magnitude as those for men. These estimates suggest that substantially larger valuations should be used in cost-benefit analyses of environmental, workplace, and job safety regulations than is current practice.

\section{REFERENCES}

Alberini, A., M. Cropper, A. Krupnick, and N. Simon (2004). "Does the value of a statistical life vary with age and health status? Evidence from the US and Canada." Journal of Environmental Economics and Management. 48:869-792.

Ashenfelter, O. and M. Greenstone (2004). "Using Mandated Speed Limits to Measure the Value of a Statistical Life." Journal of Political Economy. 112:S226-S267.

Atkinson, S.E. and R. Halvorsen (1990). "The Valuation of Risks to Life: Evidence from the Market for Automobiles." Review of Economics and Statistics. 72(1):133-136.

Bayer, P., S. Khan, and C. Timmins (2007). "Nonparametric Identification and Estimation in a Generalized Roy Model." Mimeo, Duke University Department of Economics.

Bajari, P. and M.E. Kahn (2005). "Estimating Housing Demand With an Application to Explaining Racial Segregation in Cities." Journal of Business and Economic Statistics. 23(1):20-33.

Black, D.A. and T.J. Kniesner (2003). "On the Measurement of Job Risk in Hedonic Wage Models." Journal of Risk and Uncertainty. 27(3):205-220.

Blomquist, G. (1979). "Value of Life Saving: Implications from Consumption Activity." Journal of Political Economy. 87(3):540-58.

Brown, C. (1980). "Equalizing Differences in the Labor Market." Quarterly Journal of Economics. 94(1):113-34.

Carlin, P. and R. Sandy (1991). "Estimating the Implicit Value of a Young Child's Life." Southern Economic Journal. 58(1): 186-202. 
Costa, D. and M. Kahn (2004). "Changes in the Value of Life, 1940-1980." The Journal of Risk and Uncertainty. 29(2):159-180.

DeLeire, T. and H. Levy (2004). "Worker Sorting and the Risk of Death on the Job." Journal of Labor Economics. 22(4): 925-954.

Dreyfus, M.K. and W.K. Viscusi (1995). "Rates of Time Preference and Consumer Valuations of Automobile Safety and Fuel Efficiency." Journal of Law and Economics. 38(1):79-105.

Gayer, T., J.T. Hamilton, and W.K. Viscusi (2000). "Private Values of Risk Tradeoffs at Superfund Sites: Housing Market Evidence on Learning About Risk." Review of Economics and Statistics. 82(3):439-451.

Gill, R.D. (1980). Censoring and Stochastic Integrals. Mathematical Centre Tracts, 124. Mathematical Centrum, Amsterdam.

Hakes, J. and W.K. Viscusi (2007). "Automobile Seatbelt Usage and the Value of Statistical Life.” Southern Economic Journal. 73(3):659-676.

Heckman, J.J. (1990). "Varieties of Selection Bias." American Economic Review. 80(2):313-18.

Heckman, J.J. and B. Honore (1990). "The Empirical Content of the Roy Model." Econometrica. 58:1121-1149.

Hersch, J. and T.S. Pickton (1995). "Risk-Taking Activities and Heterogeneity in JobRisk Tradeoffs." Journal of Risk and Uncertainty. 11(3):205-217.

Hersch, J. and W.K. Viscusi (1990). "Cigarette Smoking, Seatbelt Use, and Differences in Wage-Risk Tradeoffs." Journal of Human Resources. 25(2):202-227.

Hwang, H., W.R. Reed, and C. Hubbard (1992). "Compensating Wage Differentials and Unobserved Productivity.” Journal of Political Economy. 100(4): 835-858.

Kniesner, .J., W.K. Viscusi, C. Woock, and J.P. Ziliak (2006). "Pinning Down the Value of Statistical Life." Center for Policy Research Working Paper 85, Maxwell School, Syracuse University.

Li, S. (2006). "The Social Costs of the "Arms Race" on American Roads: Evidence from Automobile Demand." Mimeo, Duke University Department of Economics.

Portney, P.R. (1981). "Housing Prices, Health Effects, and Valuing Reductions in Risk of Death." Journal of Environmental Economics and Management. 8:72-78. 
Revesz, R. (1999). "Environmental Regulation, Cost-Benefit Analysis, and the Discounting of Human Lives." Columbia Law Review. 99:941-1017.

Rosen, S. (1986). "The Theory of Equalizing Differences." In Handbook of Labor Economics, Vol. 1. ed. Orley C. Ashenfelter and Richard Layard, pp.641-92. Amsterdam: North-Holland.

Roy, A.D. (1951). "Some Thoughts on the Distribution of Earnings." Oxford Economic Papers. 3:135-146.

Savage, I. (1993). "An Empirical Investigation into the Effect of Psychological Perception on the Willingness to Pay to Reduce Risk." Journal of Risk and Uncertainty. 6:75-90.

Scotten, C. and L. Taylor (2007). "Of Cab Drivers and Coal Miners: Accounting for Risk Heterogeneity in Value of Statistical Life Estimates." Mimeo.

Shogren, J.F. and T. Stamland (2002). "Skill and the Value of Life." Journal of Political Economy. 110(5):1168-1197.

Smith, V.K., M. Evans, H. Kim, and D. Taylor (2004). "Do the Near-Elderly Value Mortality Risks Differently?" Review of Economics and Statistics. 86(1):423-429.

Thaler, R. and S. Rosen (1975). "The Value of Saving a Life: Evidence from the Labor Markets." In N.E. Terleckyj (ed.), Household Production and Consumption. New York: Columbia University Press. pp.265-300.

Viscusi, W.K. (1992). Fatal Tradeoffs: Public and Private Responsibilities for Risk. New York: Oxford University Press.

. (2003). "Racial Differences in Labor Market Values of a Statistical Life." Journal or Risk and Uncertainty. 27:3:239-256.

Viscusi,, W.K. and J. Aldy (2003). "The Value of a Statistical Life: A Critical Review of Market Estimates Throughout the World." Journal of Risk and Uncertainty. 27(1):5-76.

. "Adjusting the Value of a Statistical Life for Age and Cohort Effects." RFF Discussion Paper 06-19.

Viscusi, W.K. and J. Hersch (2001). "Cigarette Smokers as Job Risk Takers." Review of Economics and Statistics. 83(2):269-280. 
Table 1

Determinants of Job Characteristics Based on DOT Data

Factor 1 SUBSTANTIVECOMPLEXITY

DATAL (complexity of function in relation to data)

GED (general educational development)

INTELL (intelligence)

NUMERCL (numerical aptitude)

REPCON (Adaptability to performing repetitive work)

SJC (sensor or judgmental criteria)

SVP (specific vocational preparation)

VERBAL (verbal aptitude)

Factor 2 MOTOR SKILLS

CLRDISC (color discrimination)

FNGRDXT (finger dexterity)

MNLDXTY (manual dexterity)

MTRCRD (motor coordination)

THINGS (complexity in relation to things)

Factor 3 PHYSICAL DEMANDS

CLIMB (climbing, balancing)

EYHNFTC (eve-hand-foot coordination)

HAZARDS (hazardous conditions)

OUT (outside working conditions)

STOOP (stooping, kneeling, crouching, crawling)

Factor 4 WORKING CONDITION

COLD (extreme cold)

HEAT (extreme heat)

WET (wet, humid)

Factor 5 CREATIVE SKILLS

ABSCREAT (abstract \& creative activities)

FIF (feelings, ideas or facts)

Factor 6 INTPEOPLE

PEOPLE (interaction with people) 
Table 2 (a)

Occupation Attributes

\begin{tabular}{|c|c|c|c|c|c|c|c|c|}
\hline Occupation & FATAL & NONFATAL & SCMPLX & MSKILL & PHYDDS & WORCON & CSKILL & INTPEOPLE \\
\hline 3-6: Pub. Admin. & 0.0018 & 0.0000 & 0.6879 & 1.1353 & -0.2425 & 0.6505 & -0.1907 & -0.2694 \\
\hline 7-22: Other Exec. & 0.0020 & 1.4982 & 0.6143 & 1.1082 & -0.4853 & -0.3941 & -0.1763 & -0.3935 \\
\hline 23-37: Management & 0.0009 & 1.3879 & 0.9138 & 1.1947 & -0.7276 & -0.4849 & -0.1829 & -0.2586 \\
\hline 44-59: Engineers & 0.0023 & 1.0150 & 1.3207 & -0.9070 & -0.4879 & -0.4232 & 0.4608 & -1.3702 \\
\hline 64-68: Mathematical and Comp Sci & 0.0004 & 0.6365 & 1.1708 & 1.3192 & -0.6439 & -0.5881 & -0.0977 & -0.2871 \\
\hline 69-83: Natural scientists & 0.0023 & 0.8725 & 1.3793 & -0.9374 & -0.3347 & 0.3333 & 0.0038 & -1.3461 \\
\hline 84-89: Health diagnosers & 0.0011 & 1.8691 & 1.8017 & -3.1622 & -0.5097 & -0.5521 & -0.4203 & -3.1264 \\
\hline 95-106: Health assess \& treat & 0.0007 & 5.1230 & 0.6012 & -0.9513 & -0.4469 & -0.5923 & -0.3494 & -0.4050 \\
\hline 113-154: Professors & 0.0005 & 0.2670 & 1.6046 & 1.4303 & -0.8375 & -0.5982 & -0.1342 & -0.8641 \\
\hline 155-159: Teachers (exc. coll.) & 0.0005 & 1.2979 & 0.9016 & 0.3525 & -0.3597 & -0.5881 & 0.9809 & -1.0559 \\
\hline 178-179: Lawyers \& judges & 0.0012 & 0.3306 & 2.0665 & 1.7181 & -0.9118 & -0.6018 & 4.1324 & -1.6702 \\
\hline 43,63,163-177,183-199: Oth. prof. spec. & 0.0011 & 2.2276 & 1.1812 & 0.1353 & -0.5487 & -0.0945 & 4.1225 & -1.2298 \\
\hline 203-208: Health tech. & 0.0009 & 8.6382 & 0.0277 & -1.0334 & -0.3174 & -0.4868 & -0.3592 & -0.1885 \\
\hline 213-225: Eng/sci tech. & 0.0020 & 4.2027 & 0.5435 & -1.4970 & -0.4499 & -0.4413 & -0.0645 & -0.7843 \\
\hline 226-235: Tech, not eng/sci & 0.0096 & 5.5567 & 0.7081 & 0.4057 & -0.5408 & -0.5718 & -0.0134 & -0.5043 \\
\hline 243: Sales supervisors & 0.0033 & 3.5027 & 0.4089 & 1.0263 & -0.2950 & -0.3658 & -0.0998 & -0.2668 \\
\hline 253-257: Sales reps and business & 0.0012 & 1.5427 & 0.6899 & 1.2582 & -0.8207 & -0.5888 & -0.3644 & 0.2252 \\
\hline 258-259: Sales reps, non-retail comm. & 0.0016 & 2.0476 & 0.2529 & 1.0859 & -0.8616 & -0.5615 & -0.3929 & 0.3773 \\
\hline 263-278: Sales work, retail \& svc. & 0.0020 & 5.3078 & -0.4732 & -0.2793 & -0.7061 & -0.5062 & -0.3788 & 0.4036 \\
\hline 283-285: Sales-related occupations & 0.0000 & 5.8560 & -0.0287 & -0.0613 & -0.8066 & -0.5784 & 0.7758 & 0.2225 \\
\hline
\end{tabular}


Table 2 (b)

Occupation Attributes

\begin{tabular}{|c|c|c|c|c|c|c|c|c|}
\hline Occupation & FATAL & NONFATAL & SCMPLX & MSKILL & PHYDDS & WORCON & CSKILL & INTPEOPLE \\
\hline 303-307: Admin. Supervisors & 0.0004 & 2.6672 & 0.1349 & 0.3182 & -0.6802 & -0.4804 & -0.3788 & -0.1069 \\
\hline 308-309: Computer operators & 0.0000 & 1.7641 & -0.0650 & -0.4041 & -0.5568 & -0.6022 & -0.4023 & -0.4457 \\
\hline 313-315: Secretaries & 0.0003 & 2.0029 & 0.3957 & -1.9561 & -0.9030 & -0.5939 & -0.4176 & -0.4713 \\
\hline 337-344: Fin. record process & 0.0002 & 2.1631 & -0.1916 & -0.4688 & -0.8965 & -0.5598 & -0.4209 & 0.1085 \\
\hline 354-357: Mail/msg dist. & 0.0025 & 11.5449 & -1.1516 & 0.5619 & -0.6374 & -0.4628 & -0.4289 & 1.1268 \\
\hline 316-336,345-353,359-389: other admin. & 0.0005 & 6.3292 & -0.3962 & 0.5455 & -0.7559 & -0.4331 & -0.3810 & 0.3642 \\
\hline 403-407: Pvt. hh service & 0.0007 & 0.0000 & -1.3641 & 0.7072 & 0.2214 & -0.5826 & -0.4251 & 1.4478 \\
\hline 413-427: Protective svc. & 0.0086 & 7.7154 & -0.6374 & 0.6563 & 0.7423 & 1.0386 & -0.4224 & 0.7100 \\
\hline 433-444: Food service & 0.0009 & 8.8127 & -0.8628 & 0.4484 & -0.3909 & 2.1472 & -0.1096 & 0.6795 \\
\hline 445-447: Health service & 0.0008 & 24.1017 & -0.8532 & -0.2811 & 0.6658 & -0.3933 & -0.3731 & 0.9321 \\
\hline 448-455: Cleaning/bldg svc. & 0.0020 & 13.8845 & -1.5140 & 0.3170 & 1.1338 & -0.2767 & -0.4196 & 1.4232 \\
\hline 456-469: Personal svc. & 0.0014 & 9.1429 & -0.4508 & -0.5895 & -0.2467 & -0.4406 & 1.3130 & 0.3487 \\
\hline 503-549: Mechanics \& repairers & 0.0053 & 15.2240 & -0.0444 & -1.3110 & 0.7587 & 0.3971 & -0.4063 & -0.6087 \\
\hline 553-599: Construction trades & 0.0068 & 22.5577 & -0.0188 & -0.9502 & 2.2933 & -0.1960 & -0.3797 & -0.2826 \\
\hline 613-699: Other precision production & 0.0029 & 13.6475 & -0.5258 & -1.0338 & 0.0501 & 1.6055 & -0.3601 & 0.2105 \\
\hline 703-779: Machine operators & 0.0024 & 22.6953 & -1.2204 & -0.3437 & -0.1057 & 0.8997 & -0.3738 & 0.9643 \\
\hline 783-799: Fabricators, inspectors & 0.0028 & 17.8286 & -1.2994 & -0.4417 & -0.0571 & 0.6781 & -0.3785 & 1.2154 \\
\hline 803-814: Motor vehicle operators & 0.0176 & 35.6393 & -1.3383 & -0.3606 & 0.7426 & -0.4457 & -0.4160 & 0.7532 \\
\hline 823-859: Other transportation & 0.0166 & 29.2157 & -1.1876 & -0.0819 & 1.1613 & 0.4532 & -0.4187 & 1.1319 \\
\hline 864-889: Construction, freight, labor & 0.0110 & 34.9962 & -1.6291 & 0.4910 & 1.0768 & 3.8833 & -0.4244 & 1.7816 \\
\hline 473-476: Farm managers & 0.0094 & 0.3968 & 0.4685 & 0.2723 & 2.3756 & -0.4168 & -0.4280 & -1.0789 \\
\hline 477-489: Farm workers & 0.0117 & 11.4986 & -1.3619 & 0.3021 & 2.6532 & -0.1571 & -0.3915 & 1.5059 \\
\hline 494-499: Forestry \& fishing & 0.0872 & 35.0779 & -1.2595 & 0.2617 & 2.6898 & 2.9723 & -0.4088 & 1.0820 \\
\hline
\end{tabular}


Table 3: Worker Attributes ${ }^{36}$

\begin{tabular}{lcccc}
\hline & \multicolumn{2}{c}{ Men } & \multicolumn{2}{c}{ Women } \\
\hline & Low Risk & High Risk & 412,307 & High Risk \\
Sample Size & 107,140 & 519,970 & 12.14 & 9.81 \\
AGage & 13.12 & 13.17 & 35.77 & 35.38 \\
MARRIED & 31.82 & 34.03 & 0.56 & 0.51 \\
UNION & 0.39 & 0.54 & 1.97 & 1.98 \\
MSA & 1.97 & 1.96 & 0.74 & 0.70 \\
FULLTIME & 0.81 & 0.70 & 0.63 & 0.66 \\
WHITE & 0.71 & 0.85 & 0.85 & 0.82 \\
HSDROP & 0.82 & 0.86 & 0.08 & 0.20 \\
HSGRAD & 0.13 & 0.22 & 0.38 & 0.46 \\
SOMECOLL & 0.27 & 0.45 & 0.38 & 0.25 \\
COLLGRAD & 0.36 & 0.26 & 0.17 & 0.08 \\
NEW ENGLAND & 0.24 & 0.07 & 0.09 & 0.09 \\
MID ATLANTIC & 0.08 & 0.08 & 0.13 & 0.11 \\
E. N. CENTRAL & 0.12 & 0.11 & 0.16 & 0.15 \\
W. N. CENTRAL & 0.14 & 0.14 & 0.12 & 0.10 \\
SOUTH ATLANTIC & 0.10 & 0.10 & 0.16 & 0.19 \\
E. S. CENTRAL & 0.16 & 0.19 & 0.05 & 0.07 \\
W. S. CENTRAL & 0.04 & 0.06 & 0.08 & 0.09 \\
MOUNTAIN & 0.08 & 0.10 & 0.09 & 0.09 \\
PACIFIC & 0.12 & 0.10 & 0.12 & 0.11 \\
\hline
\end{tabular}

\footnotetext{
${ }^{36}$ This table describes the sample of hourly wage workers, excluding all those who earn less than the federal minimum wage.
} 
Table 4a

Wage-Hedonic Model Estimates

Dependent variable: wage

\begin{tabular}{|c|c|c|c|c|}
\hline & (1) & (2) & (3) & (4) \\
\hline \multirow[t]{2}{*}{ Sample } & Men & Men & Women & Women \\
\hline & Age $18-60$ & Age $18-60$ & Age $18-60$ & Age $18-60$ \\
\hline \multicolumn{5}{|c|}{ Worker Attributes } \\
\hline \multirow[t]{2}{*}{ HSDROP } & -1.450 & -1.492 & -0.794 & -1.017 \\
\hline & $(-1.521,-1.378)$ & $(-1.562,-1.419)$ & $(-0.860,-0.723)$ & $(-1.081,-0.947)$ \\
\hline \multirow{2}{*}{ SOMECOLL } & 0.320 & 0.692 & 1.076 & 1.199 \\
\hline & $(0.240,0.392)$ & $(0.548,0.830)$ & $(1.016,1.145)$ & $(1.040,1.342)$ \\
\hline \multirow[t]{2}{*}{ COLLGRAD } & 3.013 & 2.856 & 4.423 & 4.156 \\
\hline & $(2.828,3.218)$ & $(2.648,3.079)$ & $(4.292,4.558)$ & $(3.963,4.344)$ \\
\hline \multirow[t]{2}{*}{ AGE } & 0.574 & 0.644 & 0.433 & 0.452 \\
\hline & $(0.553,0.595)$ & $(0.622,0.644)$ & $(0.417,0.450)$ & $(0.435,0.470)$ \\
\hline \multirow[t]{2}{*}{ AGE2 } & -0.006 & -0.006 & -0.005 & -0.005 \\
\hline & $(-0.006,-0.005)$ & $(-0.006,-0.005)$ & $(-0.005,-0.004)$ & $(-0.005,-0.004)$ \\
\hline \multirow[t]{2}{*}{ BLACK } & -1.335 & -1.303 & -0.503 & -0.516 \\
\hline & $(-1.444,-1.231)$ & $(-1.417,-1.199)$ & $(-0.577,-0.415)$ & $(-0.593,-0.433)$ \\
\hline \multirow[t]{2}{*}{ OTHER } & -0.990 & -0.896 & -0.204 & -0.199 \\
\hline & $(-1.190,-0.782)$ & $(-1.084,-0.691)$ & $(-0.378,-0.048)$ & $(-0.362,-0.048)$ \\
\hline \multirow[t]{2}{*}{ HISPANIC } & -1.367 & -1.416 & -0.548 & -0.584 \\
\hline & $(-1.464,-1.272)$ & $(-1.509,-1.322)$ & $(-0.638,-0.459)$ & $(-0.673,-0.497)$ \\
\hline \multirow[t]{2}{*}{ MARRIED } & 1.242 & 1.183 & 0.206 & 0.187 \\
\hline & $(1.164,1.323)$ & $(1.106,1.262)$ & $(0.145,0.267)$ & $(0.130,0.245)$ \\
\hline \multirow[t]{2}{*}{ PUBLIC } & 1.157 & 1.040 & 0.499 & 0.448 \\
\hline & $(1.011,1.304)$ & $(0.897,1.190)$ & $(0.392,0.607)$ & $(0.344,0.553)$ \\
\hline \multirow[t]{2}{*}{ UNION } & -2.489 & -2.486 & -1.877 & -1.834 \\
\hline & $(-2.689,-2.300)$ & $(-2.684,-2.296)$ & $(-2.096,-1.658)$ & $(-2.050,-1.625)$ \\
\hline \multirow[t]{2}{*}{ MSA } & 0.966 & 0.974 & 1.022 & 1.049 \\
\hline & $(0.894,1.036)$ & $(0.902,1.045)$ & $(0.964,1.085)$ & $(0.993,1.111)$ \\
\hline \multirow[t]{2}{*}{ FULLTIME } & 1.112 & 1.084 & 0.651 & 0.715 \\
\hline & $(1.010,1.206)$ & $(0.980,1.172)$ & $(0.591,0.711)$ & $(0.657,0.775)$ \\
\hline
\end{tabular}


Table 4a (continued)

Wage-Hedonic Model Estimates ${ }^{37}$

Dependent variable: wage

\begin{tabular}{|c|c|c|c|c|}
\hline Occupation Attributes & $(1)$ & $(2)$ & (3) & $(4)$ \\
\hline \multirow[t]{2}{*}{ FATAL } & 24.531 & 14.128 & -46.452 & -24.612 \\
\hline & $(16.930,32.667)$ & $(6.495,22.219)$ & $(-58.770,-33.982)$ & $(-37.084,-12.707)$ \\
\hline \multirow[t]{2}{*}{ NONFATAL } & 0.098 & -0.009 & 0.100 & 0.022 \\
\hline & $(0.093,0.104)$ & $(-0.025,0.006)$ & $(0.094,0.106)$ & $(0.005,0.039)$ \\
\hline \multirow[t]{2}{*}{ SCMPLX } & 5.679 & -1.362 & 4.274 & -1.200 \\
\hline & $(5.443,5.908)$ & $(-2.098,-0.642)$ & $(4.088,4.457)$ & $(-1.824,-0.593)$ \\
\hline \multirow[t]{2}{*}{ MSKILL } & -1.447 & -1.080 & -0.388 & -0.111 \\
\hline & $(-1.541,-1.354)$ & $(-1.372,-0.784)$ & $(-0.435,-0.340)$ & $(-0.270,0.048)$ \\
\hline \multirow[t]{2}{*}{ PHYDDS } & -0.413 & 0.655 & 0.734 & -0.744 \\
\hline & $(-0.456,-0.373)$ & $(0.535,0.767)$ & $(0.668,0.814)$ & $(-0.988,-0.534)$ \\
\hline \multirow[t]{2}{*}{ WORCON } & 0.125 & 0.011 & 0.153 & -0.087 \\
\hline & $(0.096,0.153)$ & $(-0.075,0.098)$ & $(0.124,0.182)$ & $(-0.177,-0.002)$ \\
\hline \multirow[t]{2}{*}{ CSKILL } & -0.346 & -0.328 & -0.805 & -0.248 \\
\hline & $(-0.437,-0.248)$ & $(-0.650,-0.007)$ & $(-0.864,-0.744)$ & $(-0.441,-0.034)$ \\
\hline \multirow[t]{2}{*}{ INTPEOPLE } & 2.738 & 0.228 & 0.852 & -0.228 \\
\hline & $(2.497,2.962)$ & $(-0.465,0.919)$ & $(0.610,1.069)$ & $(-1.046,0.529)$ \\
\hline \multirow[t]{2}{*}{ Constant } & 4.728 & 2.524 & 4.934 & 3.803 \\
\hline & $(4.192,5.328)$ & $(1.997,3.148)$ & $(4.391,5.477)$ & $(3.224,4.375)$ \\
\hline Worker-Occupation Attribute Interactions & No & Yes & No & Yes \\
\hline Regional & Yes & Yes & Yes & Yes \\
\hline \multicolumn{5}{|l|}{ Indicators } \\
\hline $\mathrm{R}^{2}$ & 0.3283 & 0.3502 & 0.3293 & 0.3513 \\
\hline $\mathrm{N}$ & 627110 & 627110 & 693438 & 693438 \\
\hline
\end{tabular}

\footnotetext{
${ }^{37}$ Bootstrapped $95 \%$ confidence intervals (in brackets) are clustered to reflect the fact that occupation attributes are the same for all workers in a particular occupation.
} 
Table 4b

Wage-Hedonic Model Estimates

Dependent variable: log wage

\begin{tabular}{|c|c|c|c|c|}
\hline & (1) & (2) & (3) & (4) \\
\hline \multirow[t]{2}{*}{ Sample } & Men & Men & Women & Women \\
\hline & Age $18-60$ & Age $18-60$ & Age $18-60$ & Age $18-60$ \\
\hline \multicolumn{5}{|c|}{ Worker Attributes } \\
\hline \multirow[t]{2}{*}{ HSDROP } & -0.118 & -0.119 & -0.089 & -0.102 \\
\hline & $(-0.124,-0.113)$ & $(-0.124,-0.114)$ & $(-0.094,-0.083)$ & $(-0.108,-0.097)$ \\
\hline \multirow[t]{2}{*}{ SOMECOLL } & 0.019 & 0.048 & 0.083 & 0.089 \\
\hline & $(0.014,0.024)$ & $(0.038,0.057)$ & $(0.079,0.087)$ & $(0.079,0.100)$ \\
\hline \multirow[t]{2}{*}{ COLLGRAD } & 0.128 & 0.134 & 0.274 & 0.257 \\
\hline & $(0.120,0.138)$ & $(0.123,0.146)$ & $(0.267,0.281)$ & $(0.245,0.269)$ \\
\hline \multirow[t]{2}{*}{ AGE } & 0.048 & 0.051 & 0.037 & 0.038 \\
\hline & $(0.047,0.049)$ & $(0.049,0.052)$ & $(0.036,0.038)$ & $(0.037,0.039)$ \\
\hline \multirow[t]{2}{*}{ AGE2 } & -0.001 & -0.001 & 0.000 & 0.000 \\
\hline & $(-0.001,0.000)$ & $(-0.001,-0.001)$ & $(0.000,0.000)$ & $(0.000,0.000)$ \\
\hline \multirow[t]{2}{*}{ BLACK } & -0.103 & -0.100 & -0.043 & -0.044 \\
\hline & $(-0.110,-0.096)$ & $(-0.108,-0.093)$ & $(-0.049,-0.038)$ & $(-0.049,-0.038)$ \\
\hline \multirow[t]{2}{*}{ OTHER } & -0.071 & -0.067 & -0.021 & -0.021 \\
\hline & $(-0.083,-0.060)$ & $(-0.078,-0.056)$ & $(-0.032,-0.012)$ & $(-0.031,-0.012)$ \\
\hline \multirow[t]{2}{*}{ HISPANIC } & -0.105 & -0.106 & -0.046 & -0.047 \\
\hline & $(-0.111,-0.098)$ & $(-0.112,-0.099)$ & $(-0.052,-0.040)$ & $(-0.054,-0.042)$ \\
\hline \multirow[t]{2}{*}{ MARRIED } & 0.096 & 0.093 & 0.021 & 0.019 \\
\hline & $(0.091,0.101)$ & $(0.088,0.098)$ & $(0.017,0.025)$ & $(0.016,0.023)$ \\
\hline \multirow[t]{2}{*}{ PUBLIC } & 0.084 & 0.079 & 0.047 & 0.044 \\
\hline & $(0.077,0.092)$ & $(0.071,0.087)$ & $(0.040,0.054)$ & $(0.038,0.051)$ \\
\hline \multirow[t]{2}{*}{ UNION } & -0.173 & -0.172 & -0.145 & -0.142 \\
\hline & $(-0.184,-0.162)$ & $(-0.184,-0.161)$ & $(-0.158,-0.131)$ & $(-0.155,-0.129)$ \\
\hline \multirow[t]{2}{*}{ MSA } & 0.068 & 0.069 & 0.090 & 0.091 \\
\hline & $(0.064,0.073)$ & $(0.064,0.073)$ & $(0.085,0.094)$ & $(0.087,0.095)$ \\
\hline \multirow[t]{2}{*}{ FULLTIME } & 0.114 & 0.112 & 0.087 & 0.089 \\
\hline & $(0.109,0.120)$ & $(0.106,0.118)$ & $(0.083,0.090)$ & $(0.085,0.093)$ \\
\hline
\end{tabular}


Table 4b (continued)

Wage-Hedonic Model Estimates ${ }^{38}$

Dependent variable: log wage

\begin{tabular}{|c|c|c|c|c|}
\hline Occupation Attributes & (1) & (2) & (3) & (4) \\
\hline \multirow[t]{2}{*}{ FATAL } & 0.667 & 0.388 & -2.280 & -1.123 \\
\hline & $(0.190,1.194)$ & $(-0.098,0.893)$ & $(-3.103,-1.486)$ & $(-1.984,-0.345)$ \\
\hline \multirow[t]{2}{*}{ NONFATAL } & 0.008 & 0.004 & 0.009 & 0.006 \\
\hline & $(0.008,0.009)$ & $(0.003,0.005)$ & $(0.008,0.009)$ & $(0.004,0.007)$ \\
\hline \multirow[t]{2}{*}{ SCMPLX } & 0.372 & 0.166 & 0.312 & 0.064 \\
\hline & $(0.359,0.383)$ & $(0.129,0.205)$ & $(0.302,0.323)$ & $(0.030,0.098)$ \\
\hline \multirow[t]{2}{*}{ MSKILL } & -0.110 & -0.110 & -0.029 & -0.012 \\
\hline & $(-0.115,-0.104)$ & $(-0.127,-0.093)$ & $(-0.032,-0.026)$ & $(-0.022,-0.001)$ \\
\hline \multirow[t]{2}{*}{ PHYDDS } & -0.027 & 0.030 & 0.041 & -0.025 \\
\hline & $(-0.029,-0.024)$ & $(0.022,0.038)$ & $(0.036,0.045)$ & $(-0.040,-0.010)$ \\
\hline \multirow[t]{2}{*}{ WORCON } & 0.003 & -0.007 & 0.004 & -0.007 \\
\hline & $(0.001,0.005)$ & $(-0.013,-0.001)$ & $(0.002,0.006)$ & $(-0.014,0.000)$ \\
\hline \multirow[t]{2}{*}{ CSKILL } & -0.027 & -0.038 & -0.066 & -0.047 \\
\hline & $(-0.031,-0.022)$ & $(-0.055,-0.022)$ & $(-0.070,-0.063)$ & $(-0.059,-0.035)$ \\
\hline \multirow[t]{2}{*}{ INTPEOPLE } & 0.176 & 0.148 & 0.049 & 0.005 \\
\hline & $(0.163,0.189)$ & $(0.112,0.186)$ & $(0.036,0.061)$ & $(-0.040,0.049)$ \\
\hline \multirow[t]{2}{*}{ Constant } & 1.724 & 1.630 & 1.743 & 1.688 \\
\hline & $(1.692,1.760)$ & $(1.595,1.669)$ & $(1.709,1.776)$ & $(1.652,1.725)$ \\
\hline Worker-Occupation Attribute Interactions & No & Yes & No & Yes \\
\hline Regional & Yes & Yes & Yes & Yes \\
\hline \multicolumn{5}{|l|}{ Indicators } \\
\hline $\mathrm{R}^{2}$ & 0.3944 & 0.4046 & 0.3977 & 0.4106 \\
\hline $\mathrm{N}$ & 627110 & 627110 & 693438 & 693438 \\
\hline
\end{tabular}

\footnotetext{
${ }^{38}$ Bootstrapped $95 \%$ confidence intervals (in brackets) are clustered to reflect the fact that occupation attributes are the same for all workers in a particular occupation.
} 
Table 5a

Minimum Order Statistic Estimator, First Stage (Worker Attributes)

Dependent variable: wage

\begin{tabular}{|c|c|c|c|c|}
\hline \multirow{3}{*}{ Sample } & (1) & (2) & (3) & (4) \\
\hline & Men & Men & Women & Women \\
\hline & Age $18-60$ & Age $18-60$ & Age $18-60$ & Age $18-60$ \\
\hline Worker-Occupation & No & Yes & No & Yes \\
\hline Attribute Interactions & & & & \\
\hline Constant & $\begin{array}{c}-5.624 \\
(-5.737,-5.508)\end{array}$ & $\begin{array}{c}-6.006 \\
(-6.121,-5.887)\end{array}$ & $\begin{array}{c}-3.708 \\
(-3.802,-3.610)\end{array}$ & $\begin{array}{c}-4.144 \\
(-4.240,-4.050)\end{array}$ \\
\hline HSDROP & $\begin{array}{c}-1.203 \\
(-1.268,-1.140)\end{array}$ & $\begin{array}{c}-1.254 \\
(-1.321,-1.191)\end{array}$ & $\begin{array}{c}-0.553 \\
(-0.605,-0.496)\end{array}$ & $\begin{array}{c}-0.706 \\
(-0.760,-0.649)\end{array}$ \\
\hline SOMECOLL & $\begin{array}{c}0.058 \\
(-0.004,0.117)\end{array}$ & $\begin{array}{c}0.203 \\
(0.090,0.309)\end{array}$ & $\begin{array}{c}0.181 \\
(0.131,0.231)\end{array}$ & $\begin{array}{c}0.388 \\
(0.275,0.486)\end{array}$ \\
\hline COLLGRAD & $\begin{array}{c}1.312 \\
(1.202,1.437)\end{array}$ & $\begin{array}{c}1.873 \\
(1.724,2.037)\end{array}$ & $\begin{array}{c}2.075 \\
(1.993,2.160)\end{array}$ & $\begin{array}{c}2.529 \\
(2.403,2.651)\end{array}$ \\
\hline AGE & $\begin{array}{c}0.449 \\
(0.430,0.468)\end{array}$ & $\begin{array}{c}0.458 \\
(0.439,0.478)\end{array}$ & $\begin{array}{c}0.299 \\
(0.289,0.312)\end{array}$ & $\begin{array}{c}0.308 \\
(0.295,0.321)\end{array}$ \\
\hline AGE2 & $\begin{array}{c}-0.004 \\
(-0.005,-0.004)\end{array}$ & $\begin{array}{c}-0.005 \\
(-0.005,-0.004)\end{array}$ & $\begin{array}{c}-0.003 \\
(-0.003,-0.003)\end{array}$ & $\begin{array}{c}-0.003 \\
(-0.003,-0.003)\end{array}$ \\
\hline BLACK & $\begin{array}{c}-1.007 \\
(-1.100,-0.921)\end{array}$ & $\begin{array}{c}-1.129 \\
(-1.220,-1.041)\end{array}$ & $\begin{array}{c}-0.194 \\
(-0.255,-0.127)\end{array}$ & $\begin{array}{c}-0.278 \\
(-0.341,-0.207)\end{array}$ \\
\hline OTHER & $\begin{array}{c}-0.760 \\
(-0.899,-0.603)\end{array}$ & $\begin{array}{c}-0.814 \\
(-0.955,-0.659)\end{array}$ & $\begin{array}{c}-0.088 \\
(-0.212,0.024)\end{array}$ & $\begin{array}{c}-0.189 \\
(-0.317,-0.074)\end{array}$ \\
\hline HISPANIC & $\begin{array}{c}-1.184 \\
(-1.268,-1.100)\end{array}$ & $\begin{array}{c}-1.275 \\
(-1.357,-1.190)\end{array}$ & $\begin{array}{c}-0.456 \\
(-0.526,-0.381)\end{array}$ & $\begin{array}{c}-0.532 \\
(-0.603,-0.457)\end{array}$ \\
\hline MARRIED & $\begin{array}{c}0.884 \\
(0.821,0.949)\end{array}$ & $\begin{array}{c}0.958 \\
(0.892,1.021)\end{array}$ & $\begin{array}{c}0.039 \\
(-0.006,0.088)\end{array}$ & $\begin{array}{c}0.097 \\
(0.052,0.145)\end{array}$ \\
\hline PUBLIC & $\begin{array}{c}0.344 \\
(0.231,0.445)\end{array}$ & $\begin{array}{c}0.395 \\
(0.282,0.505)\end{array}$ & $\begin{array}{c}0.162 \\
(0.086,0.233)\end{array}$ & $\begin{array}{c}0.290 \\
(0.213,0.362)\end{array}$ \\
\hline UNION & $\begin{array}{c}-2.483 \\
(-2.651,-2.307)\end{array}$ & $\begin{array}{c}-2.461 \\
(-2.628,-2.288)\end{array}$ & $\begin{array}{c}-1.564 \\
(-1.741,-1.390)\end{array}$ & $\begin{array}{c}-1.549 \\
(-1.731,-1.375)\end{array}$ \\
\hline MSA & $\begin{array}{c}0.762 \\
(0.698,0.823)\end{array}$ & $\begin{array}{c}0.826 \\
(0.762,0.887)\end{array}$ & $\begin{array}{c}0.869 \\
(0.824,0.915)\end{array}$ & $\begin{array}{c}0.928 \\
(0.884,0.974)\end{array}$ \\
\hline FULLTIME & $\begin{array}{c}0.847 \\
(0.766,0.925) \\
\end{array}$ & $\begin{array}{c}0.904 \\
(0.820,0.984) \\
\end{array}$ & $\begin{array}{c}0.492 \\
(0.448,0.537) \\
\end{array}$ & $\begin{array}{c}0.562 \\
(0.517,0.607)\end{array}$ \\
\hline $\begin{array}{l}\text { Regional } \\
\text { Indicators }\end{array}$ & Yes & Yes & Yes & Yes \\
\hline $\mathrm{R}^{2}$ & 0.1463 & 0.1530 & 0.0964 & 0.1037 \\
\hline $\mathrm{N}$ & 627110 & 627110 & 693438 & 693438 \\
\hline
\end{tabular}


Table 5b

Minimum Order Statistic Estimator, Second Stage (Occupation Attributes) ${ }^{39}$

Dependent variable: wage

\begin{tabular}{|c|c|c|c|c|}
\hline & $(1)$ & $(2)$ & (3) & $(4)$ \\
\hline \multirow[t]{2}{*}{ Sample } & Men & Men & Women & Women \\
\hline & Age $18-60$ & Age $18-60$ & Age $18-60$ & Age $18-60$ \\
\hline \multirow[t]{2}{*}{ Constant } & -2.203 & -1.628 & 2.225 & 2.218 \\
\hline & $(-3.500,0.374)$ & $(-3.042,0.740)$ & $(1.187,2.764)$ & $(1.213,3.219)$ \\
\hline \multirow[t]{2}{*}{ FATAL } & -67.145 & -59.978 & -39.747 & -58.782 \\
\hline & $(-82.070,-27.816)$ & $(-81.406,-22.040)$ & $(-65.413,-21.154)$ & $(-71.257,-36.302)$ \\
\hline \multirow[t]{2}{*}{ NONFATAL } & 0.073 & 0.033 & 0.008 & 0.002 \\
\hline & $(0.006,0.093)$ & $(-0.029,0.063)$ & $(-0.048,0.034)$ & $(-0.054,0.026)$ \\
\hline \multirow[t]{2}{*}{ SCMPLX } & -0.794 & -1.986 & -0.839 & -2.149 \\
\hline & $(-1.280,0.860)$ & $(-2.281,0.041)$ & $(-1.214,0.561)$ & $(-2.448,-0.593)$ \\
\hline \multirow[t]{2}{*}{ MSKILL } & 0.395 & 0.636 & 0.243 & 0.408 \\
\hline & $(-0.199,0.602)$ & $(-0.143,0.763)$ & $(-0.438,0.344)$ & $(-0.304,0.477)$ \\
\hline \multirow[t]{2}{*}{ PHYDDS } & 0.109 & 0.336 & -0.446 & -0.408 \\
\hline & $(-0.298,0.469)$ & $(-0.144,0.725)$ & $(-0.650,-0.059)$ & $(-0.639,-0.036)$ \\
\hline \multirow[t]{2}{*}{ WORCON } & 0.285 & 0.556 & 0.107 & 0.105 \\
\hline & $(-0.121,0.614)$ & $(0.175,0.896)$ & $(-0.157,0.368)$ & $(-0.203,0.353)$ \\
\hline \multirow[t]{2}{*}{ CSKILL } & -0.059 & 0.243 & 0.174 & 0.219 \\
\hline & $(-0.322,0.294)$ & $(-0.005,0.670)$ & $(-0.002,0.536)$ & $(0.050,0.583)$ \\
\hline \multirow[t]{2}{*}{ INTPEOPLE } & -0.617 & -1.247 & -0.322 & -0.942 \\
\hline & $(-0.918,1.376)$ & $(-1.366,1.145)$ & $(-0.468,1.327)$ & $(-0.952,0.920)$ \\
\hline
\end{tabular}

\footnotetext{
${ }^{39}$ Confidence intervals (in brackets) are based on the $2.5^{\text {th }}$ and $97.5^{\text {th }}$ percentiles of the distribution of bootstrapped parameter estimates.
} 
Table $6 \mathrm{a}$

Minimum Order Statistic Estimator, First Stage (Worker Attributes)

Dependent variable: log wage

\begin{tabular}{|c|c|c|c|c|}
\hline & $(1)$ & $(2)$ & (3) & (4) \\
\hline \multirow[t]{2}{*}{ Sample } & Men & Men & Women & Women \\
\hline & Age $18-60$ & Age $18-60$ & Age $18-60$ & Age $18-60$ \\
\hline Worker-Occupation & No & Yes & No & Yes \\
\hline \multicolumn{5}{|l|}{ Attribute Interactions } \\
\hline \multirow[t]{2}{*}{ Constant } & -0.530 & -0.564 & -0.344 & -0.382 \\
\hline & $(-0.540,-0.521)$ & $(-0.571,-0.556)$ & $(-0.351,-0.337)$ & $(-3.899,-3.874)$ \\
\hline \multirow[t]{2}{*}{ HSDROP } & -0.097 & -0.103 & -0.061 & -0.075 \\
\hline & $(-0.101,-0.092)$ & $(-0.107,-0.098)$ & $(-0.065,-0.057)$ & $(-0.080,-0.071)$ \\
\hline \multirow[t]{2}{*}{ SOMECOLL } & 0.003 & 0.026 & 0.017 & 0.035 \\
\hline & $(-0.001,0.007)$ & $(0.018,0.033)$ & $(0.013,0.020)$ & $(0.026,0.042)$ \\
\hline \multirow[t]{2}{*}{ COLLGRAD } & 0.048 & 0.100 & 0.121 & 0.160 \\
\hline & $(0.042,0.054)$ & $(0.091,0.109)$ & $(0.116,0.126)$ & $(0.151,0.168)$ \\
\hline \multirow[t]{2}{*}{ AGE } & 0.038 & 0.039 & 0.026 & 0.027 \\
\hline & $(0.037,0.040)$ & $(0.038,0.040)$ & $(0.026,0.027)$ & $(0.026,0.028)$ \\
\hline \multirow[t]{2}{*}{ AGE2 } & -0.000 & -0.000 & -0.000 & -0.000 \\
\hline & $(-0.000,-0.000)$ & $(-0.000,-0.000)$ & $(-0.000,-0.000)$ & $(-0.000,-0.000)$ \\
\hline \multirow[t]{2}{*}{ BLACK } & -0.076 & -0.088 & -0.019 & -0.027 \\
\hline & $(-0.082,-0.070)$ & $(-0.094,-0.081)$ & $(-0.024,-0.014)$ & $(-0.031,-0.022)$ \\
\hline \multirow[t]{2}{*}{ OTHER } & -0.049 & -0.054 & -0.007 & -0.016 \\
\hline & $(-0.057,-0.040)$ & $(-0.063,-0.046)$ & $(-0.015,0.000)$ & $(-0.024,-0.009)$ \\
\hline \multirow[t]{2}{*}{ HISPANIC } & -0.087 & -0.095 & -0.040 & -0.047 \\
\hline & $(-0.092,-0.081)$ & $(-0.100,-0.090)$ & $(-0.046,-0.035)$ & $(-0.053,-0.042)$ \\
\hline \multirow[t]{2}{*}{ MARRIED } & 0.068 & 0.075 & 0.008 & 0.013 \\
\hline & $(0.064,0.072)$ & $(0.071,0.079)$ & $(0.005,0.011)$ & $(0.010,0.016)$ \\
\hline \multirow[t]{2}{*}{ PUBLIC } & 0.030 & 0.032 & 0.020 & 0.031 \\
\hline & $(0.024,0.036)$ & $(0.026,0.039)$ & $(0.015,0.025)$ & $(0.026,0.035)$ \\
\hline \multirow[t]{2}{*}{ UNION } & -0.168 & -0.167 & -0.126 & -0.125 \\
\hline & $(-0.177,-0.158)$ & $(-0.176,-0.157)$ & $(-0.137,-0.114)$ & $(-0.135,-0.113)$ \\
\hline \multirow[t]{2}{*}{ MSA } & 0.060 & 0.065 & 0.077 & 0.082 \\
\hline & $(0.056,0.064)$ & $(0.061,0.069)$ & $(0.074,0.080)$ & $(0.079,0.085)$ \\
\hline \multirow[t]{2}{*}{ FULLTIME } & 0.096 & 0.101 & 0.065 & 0.072 \\
\hline & $(0.091,0.101)$ & $(0.096,0.106)$ & $(0.062,0.068)$ & $(0.069,0.075)$ \\
\hline $\begin{array}{l}\text { Regional } \\
\text { Indicators }\end{array}$ & Yes & Yes & Yes & Yes \\
\hline $\mathrm{R}^{2}$ & 0.2018 & 0.2126 & 0.1385 & 0.1507 \\
\hline $\mathrm{N}$ & 627110 & 627110 & 693438 & 693438 \\
\hline
\end{tabular}


Table 6b

Minimum Order Statistic Estimator, Second Stage (Occupation Attributes) ${ }^{40}$

\begin{tabular}{|c|c|c|c|c|}
\hline & $(1)$ & $(2)$ & (3) & (4) \\
\hline Sample & $\begin{array}{c}\text { Men } \\
\text { Age } 18-60\end{array}$ & $\begin{array}{c}\text { Men } \\
\text { Age } 18-60\end{array}$ & $\begin{array}{l}\text { Women } \\
\text { Age 18-60 }\end{array}$ & $\begin{array}{l}\text { Women } \\
\text { Age } 18-60\end{array}$ \\
\hline $\begin{array}{l}\text { Worker-Occupation } \\
\text { Attribute Interactions }\end{array}$ & No & Yes & No & Yes \\
\hline Constant & $\begin{array}{c}-0.170 \\
(-0.277,0.006)\end{array}$ & $\begin{array}{c}-0.130 \\
(-0.237,0.050)\end{array}$ & $\begin{array}{c}0.166 \\
(0.072,0.236)\end{array}$ & $\begin{array}{c}0.162 \\
(0.068,0.290)\end{array}$ \\
\hline FATAL & $\begin{array}{c}-3.980 \\
(-6.649,-1.637)\end{array}$ & $\begin{array}{c}-3.526 \\
(-6.858,-1.117)\end{array}$ & $\begin{array}{c}-1.649 \\
(-6.751,-0.701)\end{array}$ & $\begin{array}{c}-3.343 \\
(-6.964,-1.627)\end{array}$ \\
\hline NONFATAL & $\begin{array}{c}0.004 \\
(0.001,0.008)\end{array}$ & $\begin{array}{c}0.002 \\
(-0.002,0.005)\end{array}$ & $\begin{array}{c}3.434 \mathrm{E}-04 \\
(-0.004,0.004)\end{array}$ & $\begin{array}{c}-2.099 \mathrm{E}-04 \\
(-0.005,0.002)\end{array}$ \\
\hline SCMPLX & $\begin{array}{c}-0.047 \\
(-0.124,0.063)\end{array}$ & $\begin{array}{c}-0.129 \\
(-0.192,-0.003)\end{array}$ & $\begin{array}{c}-0.082 \\
(-0.127,0.032)\end{array}$ & $\begin{array}{c}-0.183 \\
(-0.225,-0.050)\end{array}$ \\
\hline MSKILL & $\begin{array}{c}0.006 \\
(-0.020,0.049)\end{array}$ & $\begin{array}{c}0.023 \\
(-0.013,0.062)\end{array}$ & $\begin{array}{c}0.012 \\
(-.035,0.035)\end{array}$ & $\begin{array}{c}0.026 \\
(-0.028,0.045)\end{array}$ \\
\hline PHYDDS & $\begin{array}{c}0.016 \\
(-.0178,0.045)\end{array}$ & $\begin{array}{c}0.026 \\
(-0.006,0.058)\end{array}$ & $\begin{array}{c}-0.037 \\
(-0.056,-0.010)\end{array}$ & $\begin{array}{c}-0.029 \\
(-0.062,-0.004)\end{array}$ \\
\hline WORCON & $\begin{array}{c}0.017 \\
(-0.010,0.041)\end{array}$ & $\begin{array}{c}0.036 \\
(0.011,0.062)\end{array}$ & $\begin{array}{c}-0.005 \\
(-0.019,0.026)\end{array}$ & $\begin{array}{c}-0.008 \\
(-0.025,0.026)\end{array}$ \\
\hline CSKILL & $\begin{array}{c}-0.015 \\
(-0.022,0.014)\end{array}$ & $\begin{array}{c}0.021 \\
(-0.002,0.048)\end{array}$ & $\begin{array}{c}0.027 \\
(-0.003,0.054)\end{array}$ & $\begin{array}{c}0.033 \\
(0.007,0.064)\end{array}$ \\
\hline INTPEOPLE & $\begin{array}{c}-0.008 \\
(-0.081,0.119)\end{array}$ & $\begin{array}{c}-0.037 \\
(-0.098,0.105)\end{array}$ & $\begin{array}{c}-0.024 \\
(-0.055,0.111)\end{array}$ & $\begin{array}{c}-0.065 \\
(-0.082,0.095)\end{array}$ \\
\hline
\end{tabular}

\footnotetext{
${ }^{40}$ Confidence intervals (in brackets) are based on the $2.5^{\text {th }}$ and $97.5^{\text {th }}$ percentiles of the distribution of bootstrapped parameter estimates.
} 
Table 7a: Value of a Statistical Life (\$ millions)

95\% Confidence Interval ${ }^{41}$

Dependent variable: wage

\begin{tabular}{|c|c|c|c|c|}
\hline Sample & $\begin{array}{c}\text { Men } \\
\text { Age } 18-60\end{array}$ & $\begin{array}{c}\text { Men } \\
\text { Age } 18-60\end{array}$ & $\begin{array}{l}\text { Women } \\
\text { Age 18-60 }\end{array}$ & $\begin{array}{l}\text { Women } \\
\text { Age 18-60 }\end{array}$ \\
\hline Worker-Occupation Attribute Interactions & No & Yes & No & Yes \\
\hline Wage-Hedonic Model & $\begin{array}{c}4.906 \\
(3.386,6.533) \\
\end{array}$ & $\begin{array}{c}2.826 \\
(1.299,4.444) \\
\end{array}$ & $\begin{array}{c}-9.290 \\
(-11.754,-6.796)\end{array}$ & $\begin{array}{c}-4.922 \\
(-7.417,-2.541) \\
\end{array}$ \\
\hline Minimum Order Statistic Estimator & $\begin{array}{c}13.429 \\
(5.563,16.414)\end{array}$ & $\begin{array}{c}11.996 \\
(4.408,16.281)\end{array}$ & $\begin{array}{c}7.949 \\
(4.231,13.083)\end{array}$ & $\begin{array}{c}11.756 \\
(7.260,14.251)\end{array}$ \\
\hline $\begin{array}{l}\text { Difference between Wage-Hedonic and } \\
\text { Minimum Order VSL estimates }\end{array}$ & $\begin{array}{c}-8.523 \\
(-11.224,-0.324)\end{array}$ & $\begin{array}{c}-9.170 \\
(-13.628,-1.318)\end{array}$ & $\begin{array}{c}-17.239 \\
(-23.003,-12.522)\end{array}$ & $\begin{array}{c}-16.678 \\
(-19.474,-11.020)\end{array}$ \\
\hline
\end{tabular}

\footnotetext{
${ }^{41}$ Bootstrapped confidence intervals in brackets.
} 
Table 7b: Value of a Statistical Life (\$ millions)

95\% Confidence Interval ${ }^{42}$

Dependent variable: log wage

\begin{tabular}{|c|c|c|c|c|}
\hline Sample & $\begin{array}{l}\text { Men } \\
\text { Age } 18-60\end{array}$ & $\begin{array}{c}\text { Men } \\
\text { Age } 18-60\end{array}$ & $\begin{array}{l}\text { Women } \\
\text { Age } 18-60\end{array}$ & $\begin{array}{l}\text { Women } \\
\text { Age } 18-60\end{array}$ \\
\hline Worker-Occupation Attribute Interactions & No & Yes & No & Yes \\
\hline Wage-Hedonic Model & $\begin{array}{c}1.756 \\
(0.500,3.138)\end{array}$ & $\begin{array}{c}1.021 \\
(-0.258,2.345)\end{array}$ & $\begin{array}{c}-5.105 \\
(-6.950,-3.321)\end{array}$ & $\begin{array}{c}-2.515 \\
(-4.441,-0.771)\end{array}$ \\
\hline Minimum Order Statistic Estimator & $\begin{array}{c}10.476 \\
(4.314,17.524)\end{array}$ & $\begin{array}{c}9.282 \\
(2.942,18.069)\end{array}$ & $\begin{array}{c}3.692 \\
(1.570,15.062)\end{array}$ & $\begin{array}{c}7.486 \\
(3.644,15.586)\end{array}$ \\
\hline $\begin{array}{l}\text { Difference between Wage-Hedonic and } \\
\text { Minimum Order VSL estimates }\end{array}$ & $\begin{array}{c}-8.720 \\
(-15.669,-2.482)\end{array}$ & $\begin{array}{c}-8.261 \\
(-16.998,-2.001)\end{array}$ & $\begin{array}{c}-8.797 \\
(-19.815,-6.231)\end{array}$ & $\begin{array}{c}-10.001 \\
(-18.029,-5.733)\end{array}$ \\
\hline
\end{tabular}

\footnotetext{
${ }^{42}$ Bootstrapped confidence intervals in brackets.
} 
Table 8a: Sensitivity Analysis, Value of a Statistical Life (\$ millions)

95\% Confidence Interval in Parentheses

Dependent variable: wage

\begin{tabular}{lcccc}
\hline Specification & \multicolumn{2}{c}{ Men } & \multicolumn{2}{c}{ Women } \\
& Minimum Order & Wage-Hedonic & Minimum Order & Wage-Hedonic \\
& Statistic Estimator & Model & Statistic Estimator & Model \\
\hline Salaried Workers & 4.617 & 7.983 & 0.047 & 42.746 \\
& $(14.436,0.473)$ & $(-7.593,23.559)$ & $(21.902,-6.354)$ & $(-5.071,90.564)$ \\
Un-trimmed Sample & 16.401 & 5.488 & 7.321 & -3.404 \\
& $(23.745,9.979)$ & $(-7.571,18.547)$ & $(14.962,4.598)$ & $(-47.803,40.995)$ \\
Age [20,30) & 7.173 & 3.013 & 7.614 & -8.427 \\
Age [30, 40) & $(10.511,2.928)$ & $(-6.082,12.108)$ & $(18.218,3.820)$ & $(-41.768,24.915)$ \\
& 9.080 & 6.422 & 8.873 & -4.719 \\
Age [40, 50) & $(15.283,5.079)$ & $(-6.181,19.025)$ & $(17.144,5.468)$ & $(-49.989,40.551)$ \\
& 13.218 & 6.952 & 9.999 & -11.040 \\
Age [50, 60) & $(19.892,4.999)$ & $(-9.422,23.326)$ & $(28.204,5.510)$ & $(-61.749,39.669)$ \\
& 7.328 & 2.660 & 3.713 & -14.241 \\
Married & $(18.251,2.429)$ & $(-15.920,21.241)$ & $(35.953,-0.875)$ & $(-68.023,39.540)$ \\
& 13.633 & 4.871 & 7.165 & -14.453 \\
Unmarried & $(18.658,5.573)$ & $(-7.671,17.413)$ & $(15.690,3.843)$ & $(-61.768,32.861)$ \\
& 7.182 & 4.899 & 8.494 & -2.680 \\
1983-1992 & $(11.227,2.751)$ & $(-6.584,16.383)$ & $(14.856,4.683)$ & $(-36.09,30.738)$ \\
& 13.544 & 2.040 & 5.992 & -9.306 \\
1993-2002 & $(19.107,5.760)$ & $(-8.189,12.269)$ & $(12.055,2.607)$ & $(-49.188,30.575)$ \\
& 4.824 & 7.821 & 9.745 & -9.157 \\
Limited Individual Attributes & $(13.242,2.100)$ & $(-6.539,22.180)$ & $(18.852,5.628)$ & $(-50.489,32.175)$ \\
No Ag, Forestry, Fishing & 2.061 & 6.288 & 4.840 & -7.083 \\
& $(8.439,1.119)$ & $(-6.906,19.481)$ & $(11.454,2.551)$ & $(-49.021,34.856)$ \\
& 19.669 & 1.670 & 3.279 & -7.281 \\
& $(29.477,-13.157)$ & $(-25.815,29.155)$ & $(29.505,-6.436)$ & $(-53.776,39.213)$ \\
\hline
\end{tabular}


Table 8b: Sensitivity Analysis, Value of a Statistical Life (\$ millions) 95\% Confidence Interval in Parentheses

Dependent variable: log wage

\begin{tabular}{|c|c|c|c|c|}
\hline \multirow[t]{2}{*}{ Specification } & \multicolumn{2}{|c|}{ Men } & \multicolumn{2}{|c|}{ Women } \\
\hline & $\begin{array}{l}\text { Minimum Order } \\
\text { Statistic Estimator }\end{array}$ & $\begin{array}{l}\text { Wage-Hedonic } \\
\text { Model }\end{array}$ & $\begin{array}{l}\text { Minimum Order } \\
\text { Statistic Estimator }\end{array}$ & $\begin{array}{c}\text { Wage-Hedonic } \\
\text { Model }\end{array}$ \\
\hline Salaried Workers & $\begin{array}{c}3.501 \\
(20.990,-0.824)\end{array}$ & $\begin{array}{c}5.452 \\
(-12.157,23.060)\end{array}$ & $\begin{array}{c}9.207 \\
(33.464,-13.112)\end{array}$ & $\begin{array}{c}47.685 \\
(6.198,89.173)\end{array}$ \\
\hline Un-trimmed Sample & $\begin{array}{c}30.039 \\
(76.427,24.211)\end{array}$ & $\begin{array}{c}2.612 \\
(-9.027,14.251)\end{array}$ & $\begin{array}{c}25.477 \\
(42.099,12.077)\end{array}$ & $\begin{array}{c}7.736 \\
(-36.581,52.052)\end{array}$ \\
\hline Age $[20,30)$ & $\begin{array}{c}6.770 \\
(10.950,3.214)\end{array}$ & $\begin{array}{c}1.607 \\
(-6.933,10.147)\end{array}$ & $\begin{array}{c}6.631 \\
(20.805,2.890)\end{array}$ & $\begin{array}{c}-5.771 \\
(-35.248,23.705)\end{array}$ \\
\hline Age $[30,40)$ & $\begin{array}{c}12.957 \\
(19.599,8.819)\end{array}$ & $\begin{array}{c}3.410 \\
(-7.872,14.692)\end{array}$ & $\begin{array}{c}9.767 \\
(22.001,5.689)\end{array}$ & $\begin{array}{c}0.229 \\
(-41.364,41.822)\end{array}$ \\
\hline Age $[40,50)$ & $\begin{array}{c}16.510 \\
(25.318,8.939)\end{array}$ & $\begin{array}{c}1.577 \\
(-12.296,15.450)\end{array}$ & $\begin{array}{c}8.363 \\
(31.725,4.185)\end{array}$ & $\begin{array}{c}-4.757 \\
(-51.146,41.631)\end{array}$ \\
\hline Age $[50,60)$ & $\begin{array}{c}19.629 \\
(25.353,11.480)\end{array}$ & $\begin{array}{c}-2.966 \\
(-19.314,13.381)\end{array}$ & $\begin{array}{c}0.692 \\
(37.066,-4.099)\end{array}$ & $\begin{array}{c}-8.018 \\
(-56.734,40.699)\end{array}$ \\
\hline Married & $\begin{array}{c}11.935 \\
(21.250,5.677)\end{array}$ & $\begin{array}{c}0.923 \\
(-10.523,12.369)\end{array}$ & $\begin{array}{c}3.079 \\
(19.239,0.577)\end{array}$ & $\begin{array}{c}-9.337 \\
(-52.308,33.634)\end{array}$ \\
\hline Unmarried & $\begin{array}{c}8.873 \\
(12.141,5.058)\end{array}$ & $\begin{array}{c}2.416 \\
(-7.035,11.866)\end{array}$ & $\begin{array}{c}8.197 \\
(15.371,4.827)\end{array}$ & $\begin{array}{c}-0.224 \\
(-29.594,29.147)\end{array}$ \\
\hline 1983-1992 & $\begin{array}{c}13.219 \\
(19.484,5.922)\end{array}$ & $\begin{array}{c}-0.428 \\
(-10.365,9.508)\end{array}$ & $\begin{array}{c}3.074 \\
(14.057,0.428)\end{array}$ & $\begin{array}{c}-5.735 \\
(-41.116,29.646)\end{array}$ \\
\hline 1993-2002 & $\begin{array}{c}8.994 \\
(15.246,4.568)\end{array}$ & $\begin{array}{c}4.074 \\
(-7.492,15.640)\end{array}$ & $\begin{array}{c}8.033 \\
(22.354,5.418)\end{array}$ & $\begin{array}{c}-4.719 \\
(-41.972,32.533)\end{array}$ \\
\hline Limited Individual Attributes & $\begin{array}{c}3.622 \\
(10.707,2.212)\end{array}$ & $\begin{array}{c}3.093 \\
(-8.581,14.766)\end{array}$ & $\begin{array}{c}4.020 \\
(13.051,1.143)\end{array}$ & $\begin{array}{c}-3.259 \\
(-41.794,35.277)\end{array}$ \\
\hline No Ag, Forestry, Fishing & $\begin{array}{c}16.638 \\
(30.035,-15.094)\end{array}$ & $\begin{array}{c}-0.745 \\
(-28.710,27.219)\end{array}$ & $\begin{array}{c}7.451 \\
(24.714,-10.541)\end{array}$ & $\begin{array}{c}-3.484 \\
(-45.438,38.470)\end{array}$ \\
\hline
\end{tabular}


Table 9: Parameter Estimates Based on Normality and Independence Assumptions

\begin{tabular}{|c|c|c|c|c|c|c|c|c|}
\hline Param & Est & S.E. & Param & Est & S.E. & Param & Est & S.E. \\
\hline$\mu_{1}$ & 0.04 & 0.01 & $\sigma_{1}$ & 3.52 & 1.12 & FATAL & -3.06 & 0.85 \\
\hline$\mu_{2}$ & 2.14 & 0.61 & $\sigma_{2}$ & 3.17 & 1.02 & NONFATAL & -0.31 & 0.02 \\
\hline$\mu_{3}$ & -2.78 & 0.81 & $\sigma_{3}$ & 2.92 & 0.81 & SCMPLX & -3.05 & 0.30 \\
\hline$\mu_{4}$ & -2.34 & 0.62 & $\sigma_{4}$ & 2.97 & 0.83 & MSKILL & -0.73 & 0.08 \\
\hline$\mu_{5}$ & 1.22 & 0.35 & $\sigma_{5}$ & 2.72 & 0.80 & PHYDDS & 2.94 & 0.21 \\
\hline$\mu_{6}$ & 0.43 & 0.14 & $\sigma_{6}$ & 2.39 & 0.64 & WORCON & 0.18 & 0.05 \\
\hline$\mu_{7}$ & 1.29 & 0.60 & $\sigma_{7}$ & 3.29 & 0.91 & CSKILL & 0.61 & 0.04 \\
\hline$\mu_{8}$ & -0.57 & 0.16 & $\sigma_{8}$ & 2.19 & 0.54 & INTPEOPLE & 2.05 & 0.22 \\
\hline$\mu_{9}$ & 3.37 & 1.19 & $\sigma_{9}$ & 3.93 & 0.91 & & & \\
\hline$\mu_{10}$ & -2.24 & 0.67 & $\sigma_{10}$ & 1.93 & 0.50 & & & \\
\hline$\mu_{11}$ & 0.49 & 0.14 & $\sigma_{11}$ & 2.38 & 0.61 & & & \\
\hline$\mu_{12}$ & 1.62 & 0.44 & $\sigma_{12}$ & 3.20 & 1.01 & & & \\
\hline$\mu_{13}$ & 0.99 & 0.30 & $\sigma_{13}$ & 2.88 & 0.77 & & & \\
\hline$\mu_{14}$ & -2.91 & 0.81 & $\sigma_{14}$ & 3.51 & 0.99 & & & \\
\hline$\mu_{15}$ & 2.86 & 0.77 & $\sigma_{15}$ & 2.76 & 0.93 & & & \\
\hline$\mu_{16}$ & -2.07 & 0.55 & $\sigma_{16}$ & 2.75 & 0.70 & & & \\
\hline$\mu_{17}$ & -1.35 & 0.44 & $\sigma_{17}$ & 1.35 & 0.43 & & & \\
\hline$\mu_{18}$ & -2.60 & 0.68 & $\sigma_{18}$ & 2.88 & 0.89 & & & \\
\hline$\mu_{19}$ & -1.94 & 0.53 & $\sigma_{19}$ & 1.72 & 0.50 & & & \\
\hline$\mu_{20}$ & -0.64 & 0.18 & $\sigma_{20}$ & 1.23 & 0.36 & & & \\
\hline$\mu_{21}$ & 0.99 & 0.29 & $\sigma_{21}$ & 3.62 & 1.02 & & & \\
\hline$\mu_{22}$ & 1.21 & 0.34 & $\sigma_{22}$ & 3.37 & 0.94 & & & \\
\hline$\mu_{23}$ & 0.58 & 0.15 & $\sigma_{23}$ & 2.34 & 0.66 & & & \\
\hline$\mu_{24}$ & -1.60 & 0.45 & $\sigma_{24}$ & 2.05 & 0.62 & & & \\
\hline$\mu_{25}$ & 0.43 & 0.12 & $\sigma_{25}$ & 2.17 & 0.71 & & & \\
\hline$\mu_{26}$ & -2.89 & 0.74 & $\sigma_{26}$ & 2.54 & 0.80 & & & \\
\hline$\mu_{27}$ & -0.80 & 0.24 & $\sigma_{27}$ & 3.21 & 0.84 & & & \\
\hline$\mu_{28}$ & -0.32 & 0.08 & $\sigma_{28}$ & 2.11 & 0.62 & & & \\
\hline$\mu_{29}$ & 2.20 & 0.58 & $\sigma_{29}$ & 2.18 & 0.60 & & & \\
\hline$\mu_{30}$ & 1.09 & 0.37 & $\sigma_{30}$ & 3.43 & 1.03 & & & \\
\hline$\mu_{31}$ & -0.26 & 0.08 & $\sigma_{31}$ & 2.84 & 0.74 & & & \\
\hline$\mu_{32}$ & 0.83 & 0.24 & $\sigma_{32}$ & 1.47 & 0.35 & & & \\
\hline$\mu_{33}$ & 1.89 & 0.53 & $\sigma_{33}$ & 2.55 & 0.58 & & & \\
\hline$\mu_{34}$ & -0.07 & 0.02 & $\sigma_{34}$ & 1.56 & 0.41 & & & \\
\hline$\mu_{35}$ & 0.44 & 0.14 & $\sigma_{35}$ & 4.10 & 1.18 & & & \\
\hline$\mu_{36}$ & -0.23 & 0.07 & $\sigma_{36}$ & 0.81 & 0.26 & & & \\
\hline$\mu_{37}$ & 0.80 & 0.21 & $\sigma_{37}$ & 1.52 & 0.35 & & & \\
\hline$\mu_{38}$ & 3.42 & 0.96 & $\sigma_{38}$ & 3.58 & 0.87 & & & \\
\hline$\mu_{39}$ & -1.05 & 0.33 & $\sigma_{39}$ & 1.97 & 0.61 & & & \\
\hline$\mu_{40}$ & -1.01 & 0.30 & $\sigma_{40}$ & 2.58 & 0.66 & & & \\
\hline$\mu_{41}$ & -1.59 & 0.42 & $\sigma_{41}$ & 2.18 & 0.49 & & & \\
\hline$\mu_{42}$ & -3.43 & 1.05 & $\sigma_{42}$ & 3.69 & 1.12 & & & \\
\hline$\mu_{43}$ & -0.03 & 0.01 & $\sigma_{43}$ & 1.83 & 0.51 & & & \\
\hline
\end{tabular}


Figure 1 - Unconditional Wage Distributions

Equal Variances Across Occupations, No Correlation

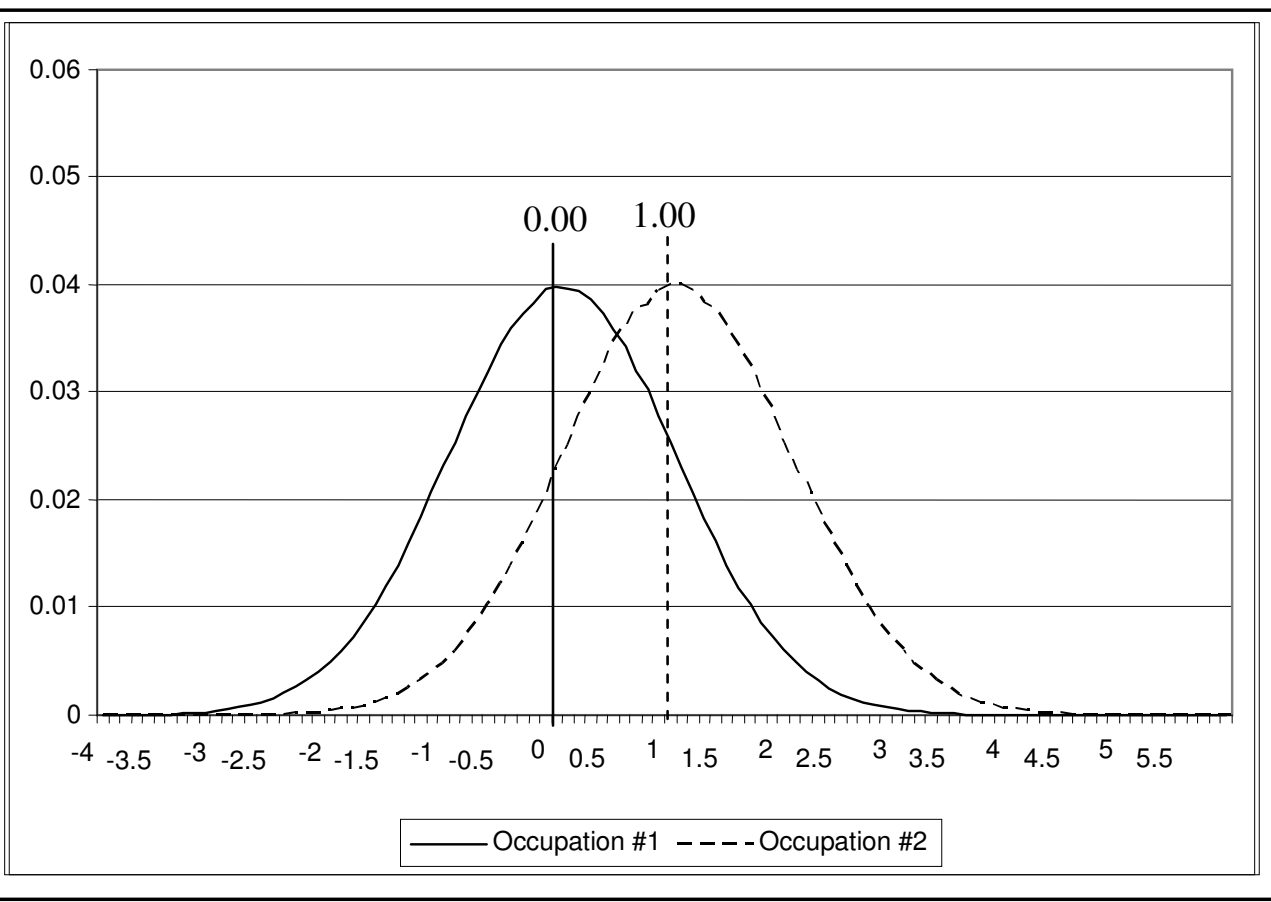

Figure 2 - Conditional Wage Distributions

Equal Variances Across Occupations, No Correlation

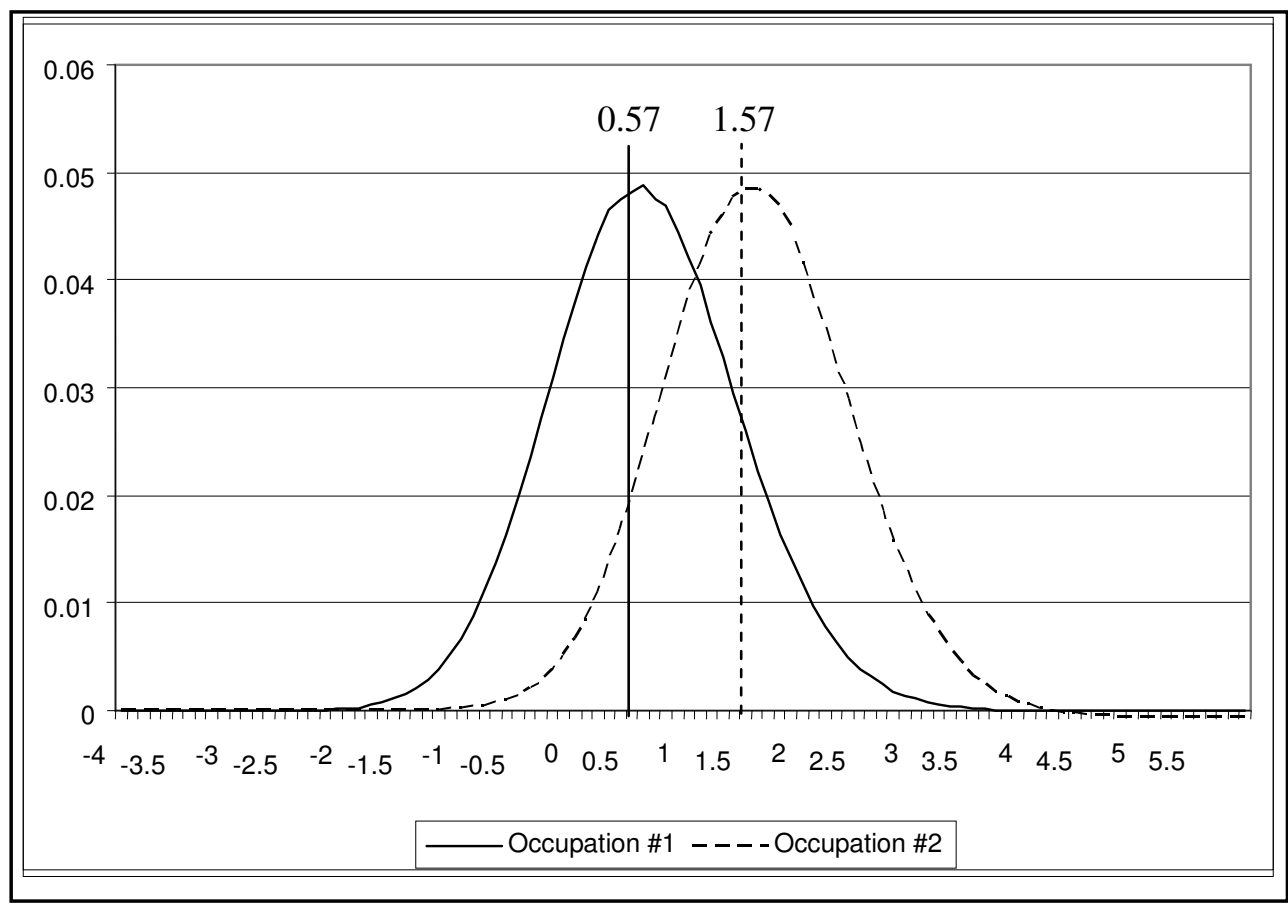


Figure 3 - Unconditional Wage Distributions

Unequal Variances Across Occupations, No Correlation

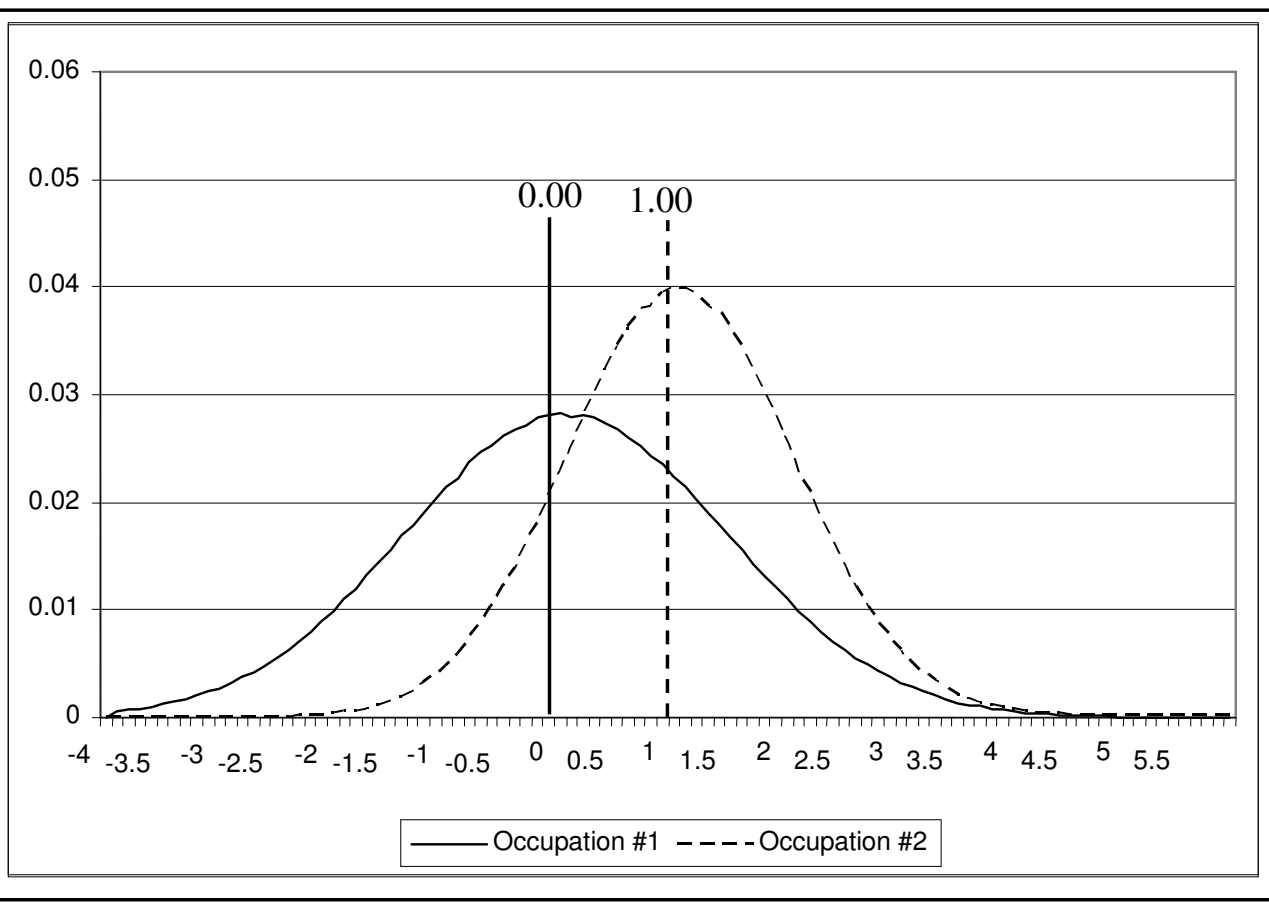

Figure 4 - Conditional Wage Distributions

Unequal Variances Across Occupations, No Correlation

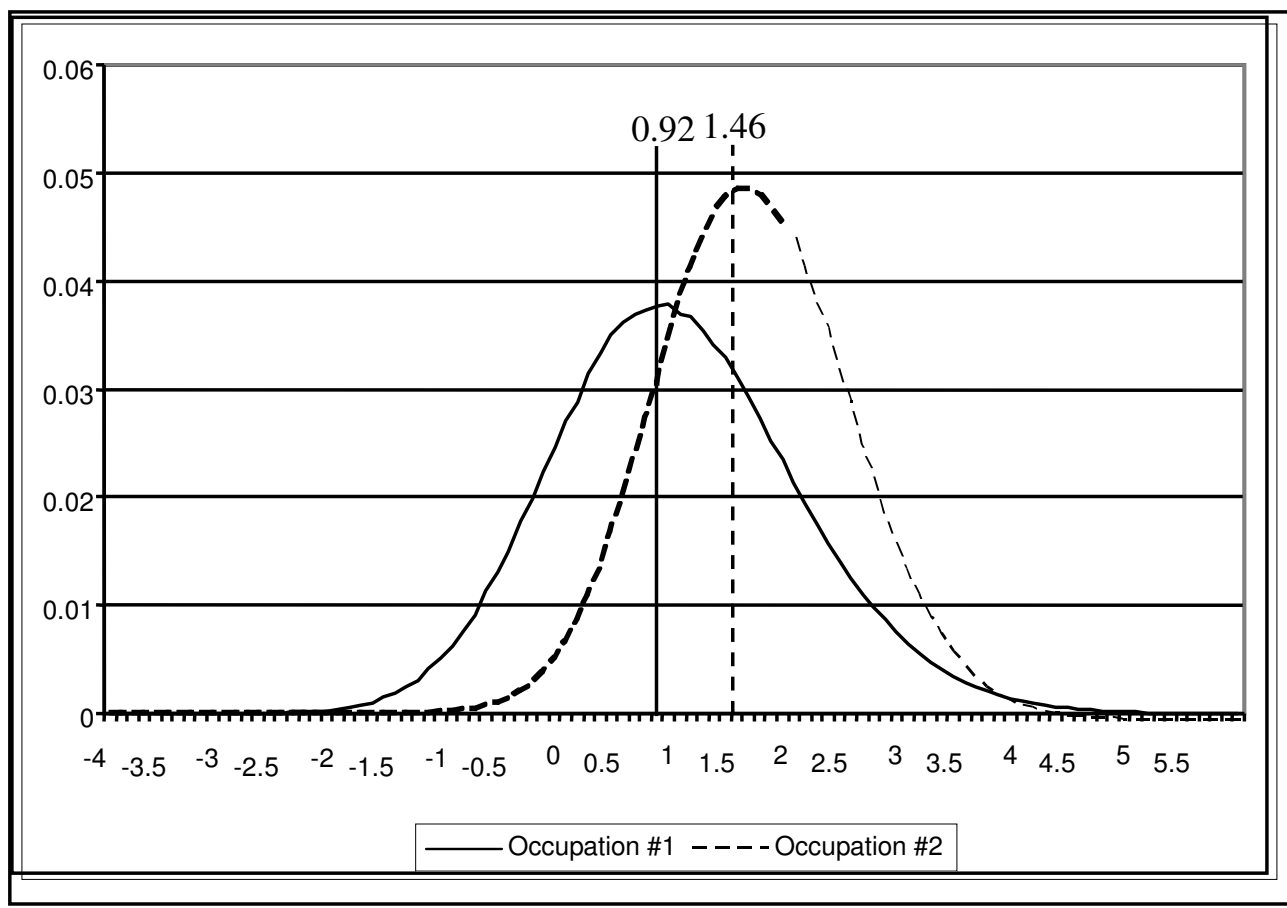


Figure 5 - Conditional Wage Distributions

Unequal Variances Across Occupations, Positive Correlation

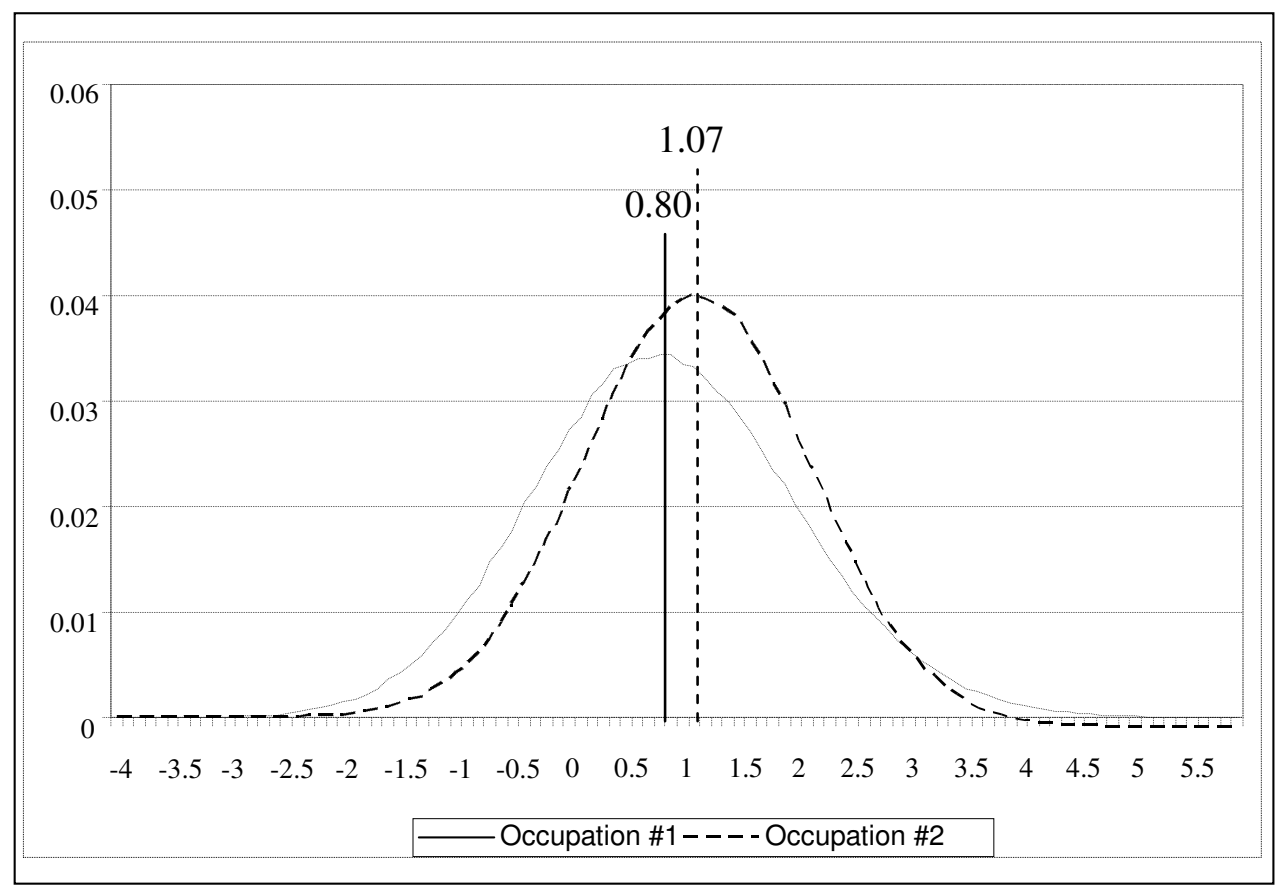

Figure 6 - Conditional Wage Distributions

Unequal Variances Across Occupations, Negative Correlation

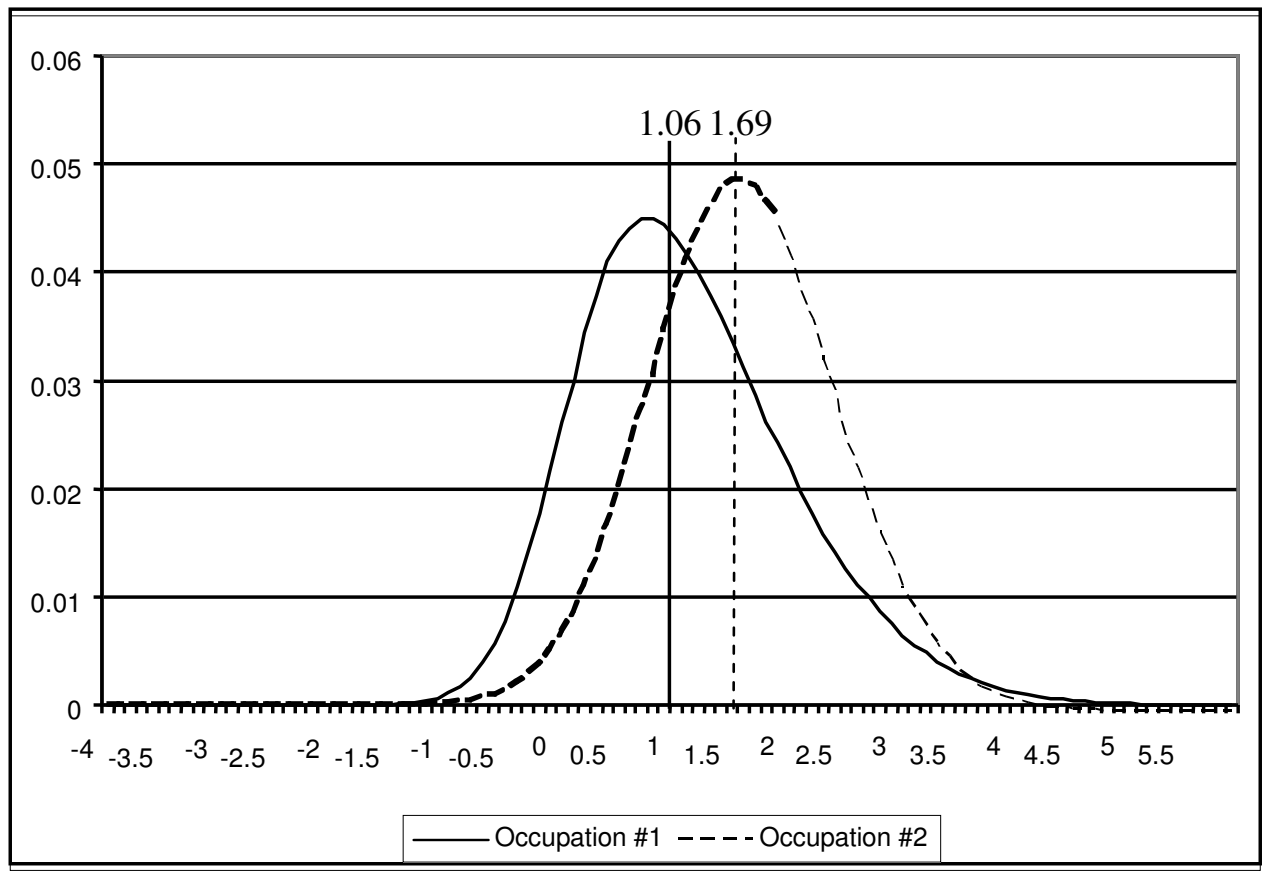


Figure 7

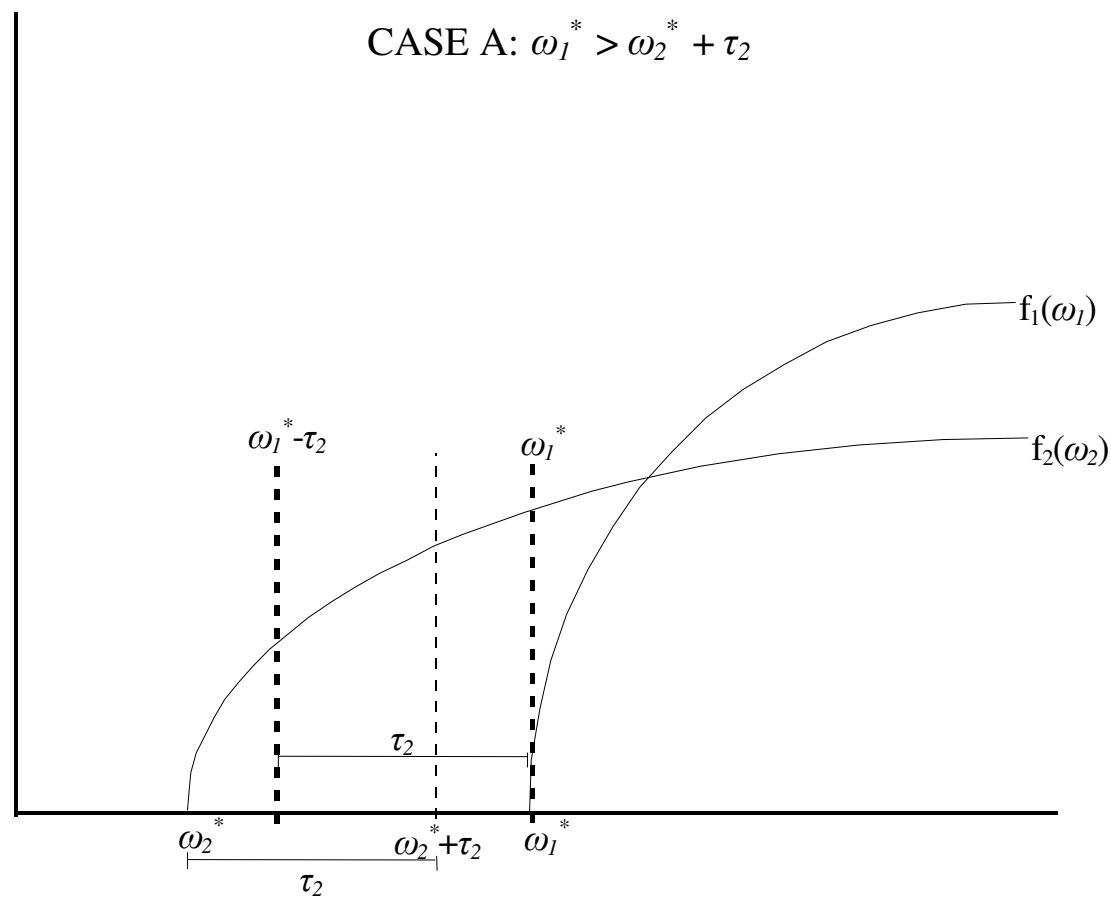

Figure 8

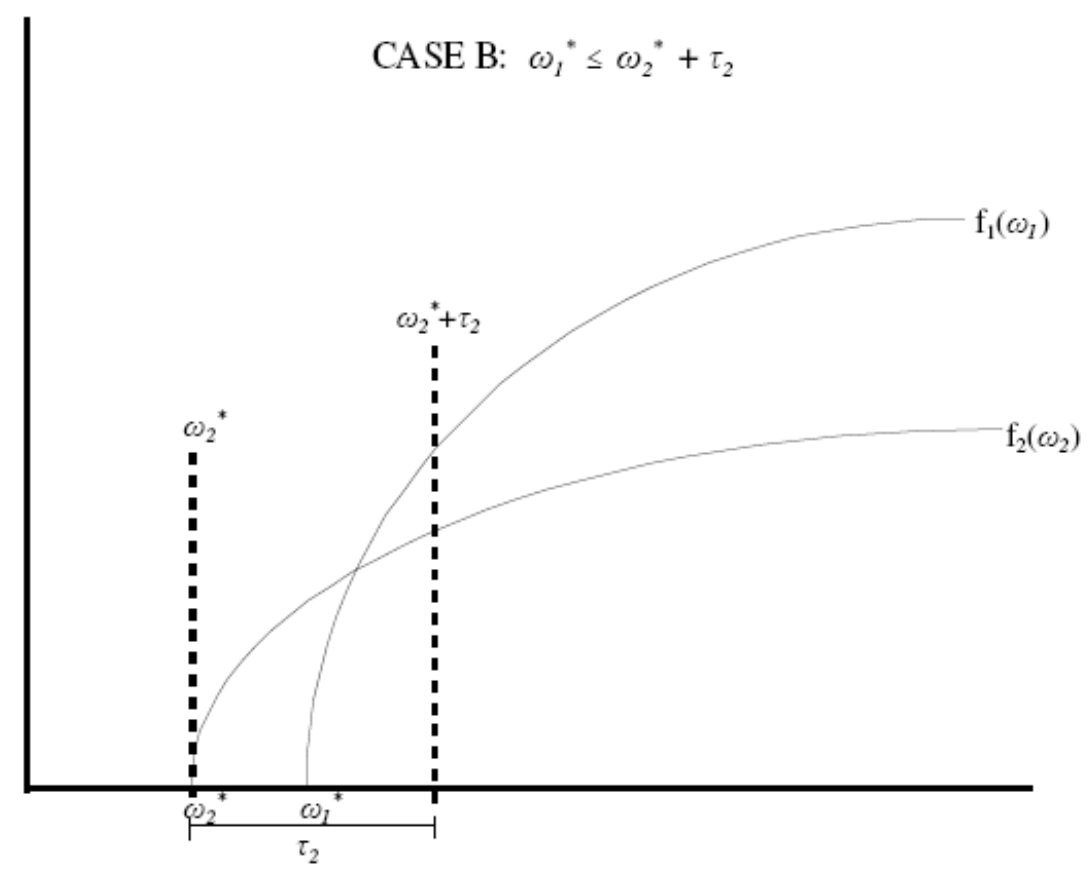

